\title{
Los usos de la fotografía en favor de la arqueología como ciencia moderna. Francia 1850-1914.
}

\author{
Susana González Reyero. \\ Universidad Autónoma de Madrid'.
}

\section{Resumen}

En este trabajo examinamos la incorporación de la fotografía a los estudios arqueológicos en Francia (1850-1914). La fotografía se consideró como un reflejo exacto de la realidad y, como tal, fue adoptada con gran entusiasmo en los viajes de exploración y estudios posteriores. Se adaptaba perfectamente a la búsqueda del dato clasificatorio y sistematizador de los planteamientos positivistas. Intervino en misiones estatales como las de Napoleón III, enmarcadas en la construcción del estado moderno francés. Con su progresiva e imparable presencia, la fotografía demostró que, más que reflejo fiel de la realidad, su imagen transmitía parte de la visión, objetivos y creencias de cada investigador. Son precisamente estas características las que hacen de ella un objeto de análisis para el investigador.

Palabras clave: Fotografía y Arqueología, Historia de la Arqueología en Francia (1850-1914), Historiografía.

\section{Résumé}

Dans ce travail nous analysons l'incorporation de la photographie aux études archéologiques en France (1850-1914). Étant donné qu'elle était considerée un reflet exacte de la réalité, la photographie est devenue une pratique de plus en plus courante dans les voyages d'exploration et dans les études postérieures. Elle était « par nature » parfaite dans la recherche du donné classificatoire et les efforts systématiques de l'approche positiviste. Ainsi, on la trouve dans les mission commandées par Napoléon III, dans une époque de construction de l'état moderne en France. Avec une présence importante et progressive, la photographie démontrait que, plus qu'un reflet fidèle de la réalité, son image transmettrait la vision, les objectifs et croyances de chaque chercheur. Mais ce sont justement ces caractéristiques qui font d'elle un sujet d'analyse.

Mots Clés: Photographie et Archéologie, Histoire de l’Archéologie en France (1850-1914), Historiographie.

\section{I-. LA definición de la Arqueología COMO UNA CIENCIA MODERNA.}

La historia de la Arqueología aparece jalonada por sucesivos descubrimientos que motivaron la apertura de nuevos campos de investigación. Pero, en primer lugar, es una historia de las ideas y los diferentes modos de mirar al pasado. En segundo lugar es una historia de métodos de investigación, del progresivo planteamiento de nuevos interrogantes y objetivos.

La Arqueología no llegó a constituirse como ciencia moderna hasta la segunda mitad del s. XIX. Para ello fue clave la aceptación de tres conceptos básicos: la considerable antigüedad de la humanidad, la teoría evolucionista de Darwin y el sistema de las tres Edades como forma de clasificación de la cultura material (Renfrew, Bahn, 1993, 36).

En este proceso el año 1859 marcó una fecha simbólica dentro de los estudios arqueológicos europeos. En aquel año Darwin publicó la obra El origen de las especies (DARWIN, 1859) que tanto influiría en las posteriores explicaciones evolucionistas unilineales. Clave para la definición de la prehistoria humana fue también la visita que recibió, en 1859, Boucher de Perthes durante sus excavaciones de Abbeville. A los ingleses J. Prestwich y J. Evans les seguirían después J. W.Flower, Godwin-Austen y Lyell. Todos ellos reconocieron, tras la visita, la autenticidad de los descubrimientos de Abbeville y Saint-Acheul. Estos autores confirmaron, así, la coetaneidad de los restos de mamíferos y de los útiles atribuidos a la manufactura humana. Como declaraba

1. Departamento de Prehistoria y Arqueología. Facultad de Filosofía y Letras. Crta. Colmenar km. 17. 28049 Madrid. E-Mail: susana.gonzalez@uam.es. 


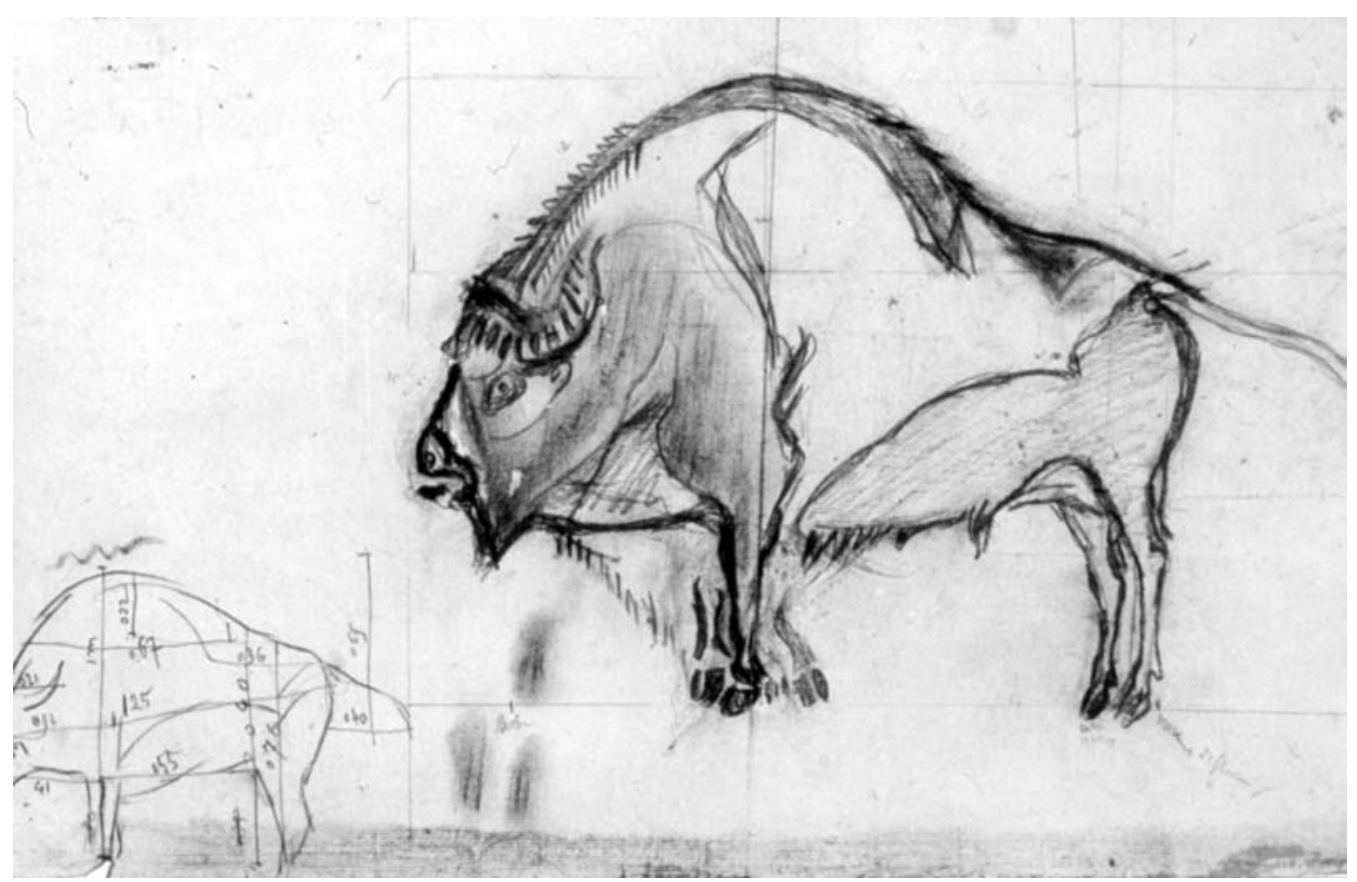

Lámina 1: El dibujo como instrumento de conocimiento. Efectuado por el abate Henri Breuil durante sus investigaciones sobre el arte rupestre peninsular. Musée de $T$ Homme, París. C-66-2733-493, Iconografía n 54-4555-1. Cliché Cl.J.Oster.

Prestwich "contemporaneidad de los útiles de sílex, productos de la concepción y del trabajo del hombre y de los restos de mamíferos (...) algunos todavía vivos pero en su mayoría hoy desaparecidos" (PRESTWICH, 1859).

Los continuos descubrimientos favorecieron la afirmación y reconocimiento oficial de la Prehistoria y el mejor conocimiento del pasado protohistórico de Europa. Así, por ejemplo, se descubrieron yacimientos tan significativos como la necrópolis de Hallstatt (Austria) en 1846 y, a partir de 1856, de La Tène (GRAN-AYMERICH, 1998, 152). Actuaciones como éstas permitieron sentar las bases de los principios de la metodología de la segunda mitad del s. XIX y buena parte del s. XX, como, por ejemplo, la cronología comparativa. Así, se dató la necrópolis de Hallstatt entre el 1000 y el 500 a.C. en función de la presencia de objetos cuya forma y decoración permitieron identificarlos como importaciones etrusco-itálicas. Poco después se produjo la importante división de la protohistoria europea en dos grandes períodos. En efecto, en el Congreso Internacional de Antropología y Arqueología Prehistórica reunido en Estocolmo (1874) Bror E.Hildebrand enunció la división que serviría como base a otras muchas posteriores, la etapa Hallstatt y La Tène (GRAN-AYMERICH, 1998, 152).

Otros significativos trabajos de la época fueron las excavaciones llevadas a cabo en Alesia entre 1860 y 1865 . Gracias a ellos Bertrand y Creuly identificaron La Tène con el último momento de la civilización céltica. La asociación de objetos reveló ser fundamental y pudo constatarse gracias al hallazgo de espadas idénticas a las del yacimiento de La Tène junto a monedas galas datables entre el 54 a.C. y el año de la batalla de Alesia, en el 52 a.C.

Los continuos descubrimientos permitieron vislumbrar la existencia de otras culturas antiguas diferentes a la griega y la romana. La Arqueología se definía poco a poco y se diferenciaba, cada vez más, de la Filología y de la Historia. La intensidad de estos descubrimientos haría necesaria la constitución de un Museo de Antigüedades Nacionales (GRAN-AYMERICH, 1998, 153). Así, en 1865 A.Bertrand asumió la dirección de la comisión que debía organizar este Museo en Francia.

\section{LAS PRIMERAS INCORPORACIONES DE LA FOTOGRAFÍA POR LOS ARQUEÓLOGOS FRAN- CESES (1839-1875).}

La fotografía se aplicó desde momentos muy tempranos a la arqueología y la reproducción de los nuevos objetos que se estaban descubriendo (Ver Lám. 3). Desde el anuncio público de su invención, en 1839, se plantearon numerosas áreas científicas en las que podía ser de gran utilidad. El entusiasmo que suscitó puede observar- 
se en numerosos testimonios de la época. Así, Ernest Lacan, conocido crítico francés de la época, recordaba, durante la Exposición Universal de 1855 (LACAN, 1856) la utilidad de la fotografía para la reproducción de obras de arte y diversas ciencias como la geología y las ciencias naturales: "En considérant l'exactitude des reproductions photographiques et la beauté des dessins obtenus, il devait naturellement venir à l'esprit des savants d'employer ce moyen puissant pour les besoins de la science. Quel secours pour la géologie, pour la botanique, pour l'histoire naturelle!” (AUBENAS, 1999b, 184).

\section{-.J. Boucher de Perthes.}

Uno de los primeros y significativos casos de la intervención de la fotografía en un debate histórico-arqueológico lo proporciona Boucher de Perthes. En 1837 este investigador francés comenzó sus trabajos en Abbeville. Poco después encontró un nivel caracterizado por numerosos restos animales, cerámicos y útiles de piedra. Pronto, entre los numerosos descubrimientos que se sucedían, identificó los primeros instrumentos "antédiluviens". Estos hallazgos delataron la presencia de hachas pulimentadas de época neolítica. Sin embargo, habría que esperar hasta junio de 1842 para poder encontrar in situ un bifaz paleolítico (ScHNAPP, 1993, 312).

Las hipótesis de Boucher de Perthes sobre la manufactura humana de estos útiles fueron objeto de una considerable incredulidad. En efecto, los descubrimientos que había realizado en la región de Abbeville (río Somme) estaban siendo objeto de duras críticas y sus conclusiones fueron muy discutidas. El 27 de Abril de 1.859 Boucher de Perthes recibió la visita de varios eruditos ingleses entre los que se encontraba el geólogo Joseph Prestwich.

Convencido de la manufactura humana de esos útiles y con la finalidad de demostrar ante la comunidad científica los descubrimientos de Boucher de Perthes, Prestwich realizó una fotografía del corte de Saint-Acheul. En ella podemos observar cómo un obrero señalaba con el dedo los útiles, todavía en su lugar de hallazgo original. La segunda fotografía de Prestwich destacaba un bifaz al lado de la impronta que había dejado sobre la tierra (FEYLER, 1993, 190). A pesar del debate que generó el trabajo de Boucher constituye la primera reflexión de conjunto sobre la estratigrafía aplicada a la arqueología: "Buscamos en cada una de las capas los indicios de la historia de sus generaciones. Las capas más profundas nos ofrecerán así las generaciones más antiguas" (SCHNAPP, 1993, 312).
Aunque antes que él se había intuido la importancia de la estratigrafía nadie había insistido, con tanta determinación, en el carácter demostrable de las observaciones estratigráficas. Ilustrando sus demostraciones mediante estratigrafías, describiendo, como un geólogo, la posición y el contenido de cada estrato que estudiaba, Boucher sentó las bases de la arqueología estratigráfica. El investigador francés atribuyó, a diferencia de la tradición escandinava, una importancia secundaria a la tipología (SCHNAPP, 1993, 313).

En este debate, la fotografía desempeñó un papel importante. Incluso se ha señalado cómo se trataría del primer uso de la fotografía en arqueología prehistórica (FEYLER, 1993, 190). A raíz de las declaraciones inglesas tras esta visita los eruditos franceses tuvieron que reconocer la veracidad de los argumentos de Boucher de Perthes, negados desde 1846 con las Antiquités celtiques et antédiluviennes (1847-1864). La fotografía constituyó una prueba que ayudó a Perthes y a los investigadores británicos a corroborar y hacer prevalecer su opinión frente a la postura, más reticente, de otros colegas.

\section{-. Félix de Saulcy y Auguste Salzmann.}

Otra importante intervención de la fotografía en los estudios históricos la protagonizaron F.de Saulcy y A.Salzmann. Félix de Saulcy llegó a Siria en 1850, visitando a continuación Galilea y el Mar Muerto (VVAA, 1982; DE SAULCY, 1853). En Jerusalén De Saulcy declaró haber identificado la tumba de los reyes de Judea y dibujó una planta de los restos, que levantó una gran polémica en los medios eruditos de la época.

Formado como pintor, el alsaciano Auguste Salzmann ha sido destacado entre los viajerosfotógrafos por el interés "claramente arqueológico" (Rouillé, 1989, 136) que traduce su obra. Su interés por las antigüedades era anterior; de hecho había viajado a Egipto, en 1851, para adquirir antigüedades para el futuro Museo Unterlinden de Colmar. Durante este viaje Salzmann conoció a Mariette y pudo contemplar los trabajos que éste estaba llevando a cabo (Aubenas, 1999, 30).

Salzmann conocía la polémica que había suscitado la teoría del arqueólogo francés De Saulcy sobre la arquitectura de Jerusalén y el hecho de que se había negado toda validez a sus dibujos y mapas. Salzmann pidió una misión al Ministerio de Instrucción Pública y llegó a Jerusalén en septiembre de 1853 con el propósito de sustituir los dibujos por fotografías (Rouillé, 1989, 136). Con su asistente Durheim realizó aproximada- 


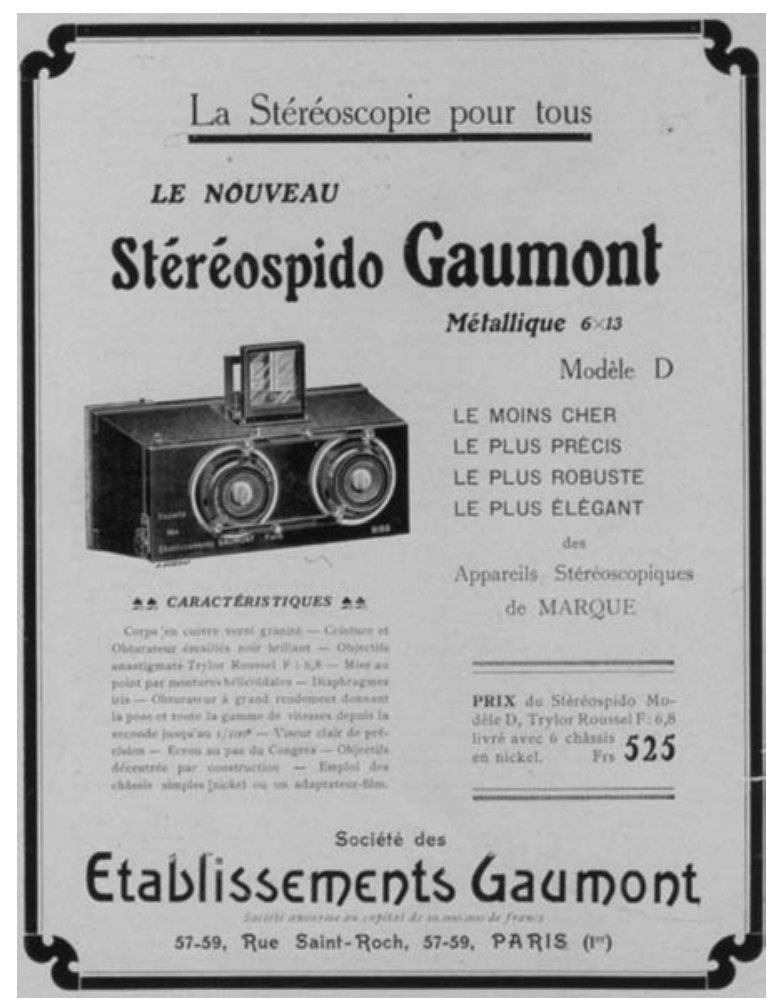

Lámina 2: Aparato fotográfico para la realización de pares estereoscópicos, de la firma francesa Gaumont.

mente 200 calotipos. La obra resultante (1854) contó con 178 láminas reproducidas en el taller de Blanquart-Evrard en Lille. Finalmente, se realizó una gran edición con texto y 174 fotos de 24 x $34 \mathrm{~cm}$. y una pequeña edición con fotografías de 16 × $22 \mathrm{~cm}$. Sus resultados, que confirmaban las teorías de Saulcy, llevaron el título de Jérusalem. Étude et reproduction photographique des Monuments de la Ville Sainte depuis lépoque judä̈que jusqúà nos jours par Auguste Salzmann (JAMmES, 1981, 93).

Existe una gran diferencia entre la obra de Salzmann y la fotografía de viajes. En efecto, mientras que en las fotografías de viajes dominaba un cierto carácter anecdótico y pintoresco, las de Salzmann estaban pensadas para sostener una tesis, para intervenir en un debate científico (Jammes, 1981, 93; Rouillé, 1989, 137). Así, la publicación de Salzmann ha sido señalada como la primera obra con fotografías en la que se observa una vocación explícitamente arqueológica (Rouillé, 1986, 55).

La obra de Salzmann tenía, pues, una clara intencionalidad: ayudar a demostrar las teorías de F.Saulcy. Con una documentación fotográfica realizada explícitamente con esta finalidad arqueológica, estaba más dirigida a un público erudito que a los amantes de libros de viajes (JAmmes, 1981, 93). Aunque hoy sabemos que en gran parte las tesis de Saulcy estaban equivoca- das, las fotografías consiguieron convencer a gran parte de los eruditos de la época. El fotógrafo alsaciano actuó siempre de una manera muy metódica. Ante un mismo edificio, realizaba una vista general, un plano más cercano y, finalmente, un número variable de detalles. Estas múltiples vistas de un monumento dado, que ahora parece usual, constituía una novedad en la arqueología de la época. Salzmann utilizó además la luz de la mejor manera posible, tendiendo a ofrecer siempre un rico juego de volúmenes. Como se puede observar en las fotografías del recinto del templo de Jerusalén, Salzmann buscó la luz rasante que evidenciara la estructura y el acabado del edificio (NECCI, 1992, 17).

El francés prestó una especial atención a la que por entonces se creía la tumba de los reyes de Judea. La investigación posterior ha desmentido esta identificación realizada por De Saulcy y que Salzmann intentó corroborar mediante la fotografía. Ante este monumento, central en la polémica generada, Salzmann realizó una secuencia fotográfica con vistas del exterior de la tumba, del patio interior, detalles de las decoraciones de la tumba y primeros planos de fragmentos del sarcófago (su cubierta y de un fragmento de su puerta). Algunas de estas tomas se presentaron como la evidencia del origen judío de la tumba (NIR, 1985, 57). Este ejemplo muestra cómo se producía el acercamiento de Salzmann respecto al tema a fotografiar. Poco a poco iba avanzando desde el conjunto hasta los detalles, cada vez más significativos, que encerraban la clave de lo que quería demostrar; arrastraba, así, al lector hacia su teoría. Del conjunto a la parte más significativa, su técnica era el equivalente al zoom-in o dolly-in del cine (NIR, 1985, 57). Todas estas vistas constituían para él la prueba en el debate histórico-arqueológico generado sobre el origen judío de la tumba.

Una vez superado el debate, Salzmann volvió a Tierra Santa en 1863 con Félix de Saulcy, los arqueólogos C.Gaillardot y V.Guérin y el arquitecto Haussard. El tema al que la nueva misión dedicó su atención fue la tumba de los reyes de Jerusalén. De Saulcy intervino con excavaciones y descubrió un sarcófago con inscripciones, atribuido por él a la hermana del rey David y que hoy sabemos perteneció en realidad a Helena de Adiabene, cristiana del s. I d.C. De Saulcy llevó al Louvre numerosos objetos encontrados durante la misión, constituyéndose la primera galería judaica del museo (Gran-Aymerich, 1998, 192).

Posteriormente, Salzmann prosiguió sus trabajos arqueológicos en Rodas, de 1858 a 1867. En efecto, en el mes de julio de 1859 descubrió la necrópolis de Camiros y comenzó una exca- 
vación de grandes dimensiones. Los resultados de estos trabajos se publicaron finalmente en 1875 en Detaille, editor de París (Foliot, 1986, 36) con el nombre de Nécropole de Camiros, journal des fouilles, notablemente ilustrada para la época.

En resumen y frente al común de viajerosfotógrafos de este período podemos señalar la finalidad científica que presidió las actuaciones de Salzmann. Al valor artístico y documental de los testimonios aportados por los primeros viajeros fotográficos Salzmann añadió una indudable dimensión científica (JAMMES, 1981, 93).

\section{III-. LA ARQUEOLOGÍA Y LA DEFINICIÓN DEL ESTADO MODERNO: LAS MISIONES CIENTÍFICAS DE NAPOLEÓN III.}

A lo largo del s. XIX las ideas liberales y el concepto del Estado-nación incrementaron en Europa la conciencia de la necesidad de la búsqueda de los orígenes nacionales. En efecto, la recuperación del pasado ayudaría a la construcción del presente (Pasamar, Peiró, 1987, 6). La Historia pasaría a formar parte de la cultura nacional frente al universalismo de momentos anteriores. En este proceso el año 1861 ha sido señalado en Francia como un annus mirabilis para la investigación arqueológica francesa. Esto se debe, en gran parte, a las tres grandes misiones encargadas por el emperador Napoleón III y a la inauguración del museo Napoleón III (GRANAYMERICH, 1998, 191).

La importancia de estas misiones radicó en que emprendían investigaciones de gran alcance sobre áreas tradicionales como el mundo griego. Pero además comenzó la investigación en zonas nuevas como Fenicia. Las tres misiones principales fueron, por una parte, las confiadas a Léon Heuzey y G.Perrot sobre el mundo griego y, por otra, la de E. Renan, que inauguró las excavaciones en Fenicia. En dos de las tres grandes misiones -Perrot y Renan- se incluyó la fotografía como técnica al servicio de la documentación de las excavaciones.

\section{-. La mission de Georges Perrot.}

Georges Perrot (1832-1914) se formó en la École Normale Supérieure de París y destacó como helenista y defensor de una historia "científica", basada en métodos de análisis rigurosos. Después de la derrota franco-prusiana mostró una preocupación constante por mejorar la calidad de la ciencia francesa. Fue el primero en recorrer la isla de Thasos, dentro de la actividad de la Escuela Francesa de Roma, con la finalidad de documentar sus restos antiguos.
En 1861 consiguió una importante misión gracias al epigrafista Léon Renier, que aconsejaba en esos años a Napoleón III en su redacción de la Histoire de César. Destacamos el importante uso de la fotografía que se aprecia en los resultados de esta misión a Asia Menor, publicados en la Exploration archéologique de la Galatie et de la Bithynie, d une partie de la Mysie, de la Phyrgie, de la Cappadoce et du Pont, exécutée en 1861 et publié sous les auspices du Ministère d' Instruction Publique (Perrot, Guillaume, Delbet, 1872). En efecto, Perrot emprendió la misión acompañado por un arquitecto, E.Guillaume y J.Delbet, médico y autor de las fotografías.

Una parte significativa de los esfuerzos de la misión se destinaron a documentar y reconstituir el templo de Augusto y de Roma. Guillaume se encargó de reunir todos sus restos mientras que Perrot transcribía el texto del testamento de Augusto conservado en sus muros. La finalidad última de esta misión era descubrir las huellas del itinerario seguido por el ejército de César -objeto de interés para la Historia que elaboraba Napoleón III- y recopilar el testamento político de Augusto en Ancyre-Ankara (GRANAymerich, 2001, 521). La reproducción cuidada de este texto en la memoria final de la misión mereció los elogios de la época. Incluso sabemos que Mommsen reconoció que era el más exacto y completo que se había realizado (GRANAYMerich, 1998, 180).

En Anatolia, la misión llegó a la ciudadela hitita de Bogazköy y Delbet tomó fotografías de este importante núcleo hitita, realizando así la primera documentación fotográfica de sus bajorrelieves. También obtuvieron una importante documentación gráfica -dibujos y fotografias- del yacimiento hitita de Euyuk. Apoyándose en estas primeras fotografías de Euyuk y de Bogazköy, Perrot revelaba al mundo erudito la civilización hitita y abría un nuevo campo a la investigación.

Gracias a las observaciones realizadas durante este viaje, Perrot comenzó a vislumbrar los importantes lazos que habían existido entre Grecia y las civilizaciones orientales. Asia Menor se convertía, así, en la cadena entre Oriente y Occidente (GRAN-AYMERICH, 1998, 180). Su misión es comprensible dentro de la actividad de una renovada arqueología francesa. El uso de la fotografía se integró dentro de los principios científicos que se estaban haciendo imprescindibles en la nueva actividad arqueológica.

La influencia que el investigador comenzó a conceder a las civilizaciones orientales constituía una asombrosa novedad. De esta forma, en su discurso de toma de cargo como profesor en la 
Sorbonne en 1876, Perrot afirmó cómo: "no es en Grecia donde hay que buscar los verdaderos orígenes de la civilización, sino en Oriente". La repercusión posterior de estos planteamientos sería, como sabemos, muy considerable. El paulatino descubrimiento de Oriente propició que se buscasen, en estas tierras, las raíces del mundo occidental (GRAN-AYMERICH, 2001, 522).

\section{-. La mission de Léon Heuzey.}

Helenista y orientalista (1831-1922) este antiguo alumno de la École Normale Supérieure de París fue elegido membre de la Académie des Inscriptions et Belles-Lettres en 1874. Desde esta posición, aseguró los medios necesarios para varias misiones científicas, como la de Sarzec en Tello (Lagash). Su actuación fue igualmente determinante en la creación del Departamento de antigüedades orientales del Museo del Louvre que, poco después, pasó a dirigir (GRANAYMERICH, 2001, 338).

La misión de Heuzey abarcó Macedonia, Tracia, Iliria, Epiro y Tesalia. De especial importancia resulta la realización de mapas topográficos trazados por el arquitecto H.Daumet y que se incluyeron en la publicación resultante; la Mission archéologique de Macédonie (Heuzey, DAUMET, 1876). Durante la misión tuvieron lugar importantes descubrimientos como las tumbas decoradas de Pidna, la ciudad real de Palatitza, los bajorrelieves de Pharsale así como las primeras estelas arcaicas encontradas en la parte septentrional de Grecia (Gran-Aymerich, 1998, 180).

La parte gráfica de esta obra consistió en grabados realizados a partir de dibujos. Quizás el hecho de que fuese un arquitecto quien se encargaba de la parte gráfica pudo influir en la no adopción de la fotografía y en el hecho de que se reprodujesen, sobre todo, vistas de reconstrucciones arquitectónicas. El mismo Heuzey declaró "me era indispensable la colaboración de un arquitecto para el dibujo de los monumentos" (Heuzey, Daumet, 1876, 2). La adecuación del dibujo arquitectónico a sus objetivos parece, pues, haber sido en este caso clave ya que, en otros estudios, Heuzey aplicó recurrentemente la fotografía.

En cuanto a la arqueología peninsular Heuzey se interesó por las antigüedades del Cerro de los Santos, descubiertas en 1869. Tras una serie de acontecimientos bastante conocidos, su autenticidad fue puesta en duda por los eruditos europeos. Sin embargo, tras un viaje a España en el que Heuzey tuvo la oportunidad de estudiar los originales del Museo Arqueológico Nacional, el francés pudo elaborar un estudio que le llevó a ser, junto a Hübner, el primer investigador en confirmar la autenticidad de las esculturas.

Al mismo tiempo, Heuzey comenzó a intuir la importancia que habría tenido la influencia griega y púnica en la configuración de la cultura del Cerro de los Santos. En este sentido y ante la ausencia de un nombre propio denominó esta cultura como "demi-civilisation gréco-phénicienne". En todo caso, la situaba antes de la conquista romana de la Península (Heuzey, 1897, 6). En el detallado informe presentado ante la Académie des Inscriptions et Belles-Lettres en 1897 Heuzey reprodujo dos fotografías de la Dama de Elche -realizadas por P.Paris- mostrándola frontalmente y de espaldas. Las fotografías constituían, una vez más, la prueba que apoyaba los argumentos desplegados en favor de la especificidad del arte prerromano de España. La finalidad principal era vencer, definitivamente, la controversia generada ante la falsificación de esculturas por parte del relojero de Yecla, D. Juan y Amat. Pero también se perseguía implicar a la administración pública francesa de forma que destinase los medios financieros necesarios para continuar los estudios sobre esta cultura. La evidente importancia y belleza de la pieza que Heuzey presentaba ante la Académie mostraba la relevancia cultural de la protohistoria hispana. De esta forma abría, con el reconocimiento de la cultura ibérica, un nuevo campo de investigación. Las fotografías parecían ser, una vez más, un argumento fundamental para la demostración.

\section{-. La mission de Ernest Renan.}

Ya antes de ser designado para esta mission, Renan había depositado, en el Institut de France, su Mémoire sur lorigine et le caractère véritable de thistoire phénicienne en 1857. En ella, Renan llamaba la atención sobre el interés de posibles excavaciones en Fenicia y, sobre todo, en Biblos (Gran-Aymerich, 1998, 193). Esta memoria se enmarcaba en el ambiente generado tras el importante descubrimiento fortuito, en 1855, del sarcófago de Eshmounazar, rey de Sidón en el s. $\mathrm{V}$ a.C. El sarcófago permitió documentar la primera inscripción semita descubierta en la misma Fenicia y tuvo un considerable eco entre los círculos eruditos de la época, siempre anhelantes de nuevas inscripciones y textos. En este sentido, el acercamiento de Renan a la arqueología fenicia estuvo muy influido por la filología. En efecto, para él "el estudio de las lenguas es el primer e indispensable instrumento del método histórico" (RENAN, 1890, 847).

La mission de Renan estuvo marcada por cir- 


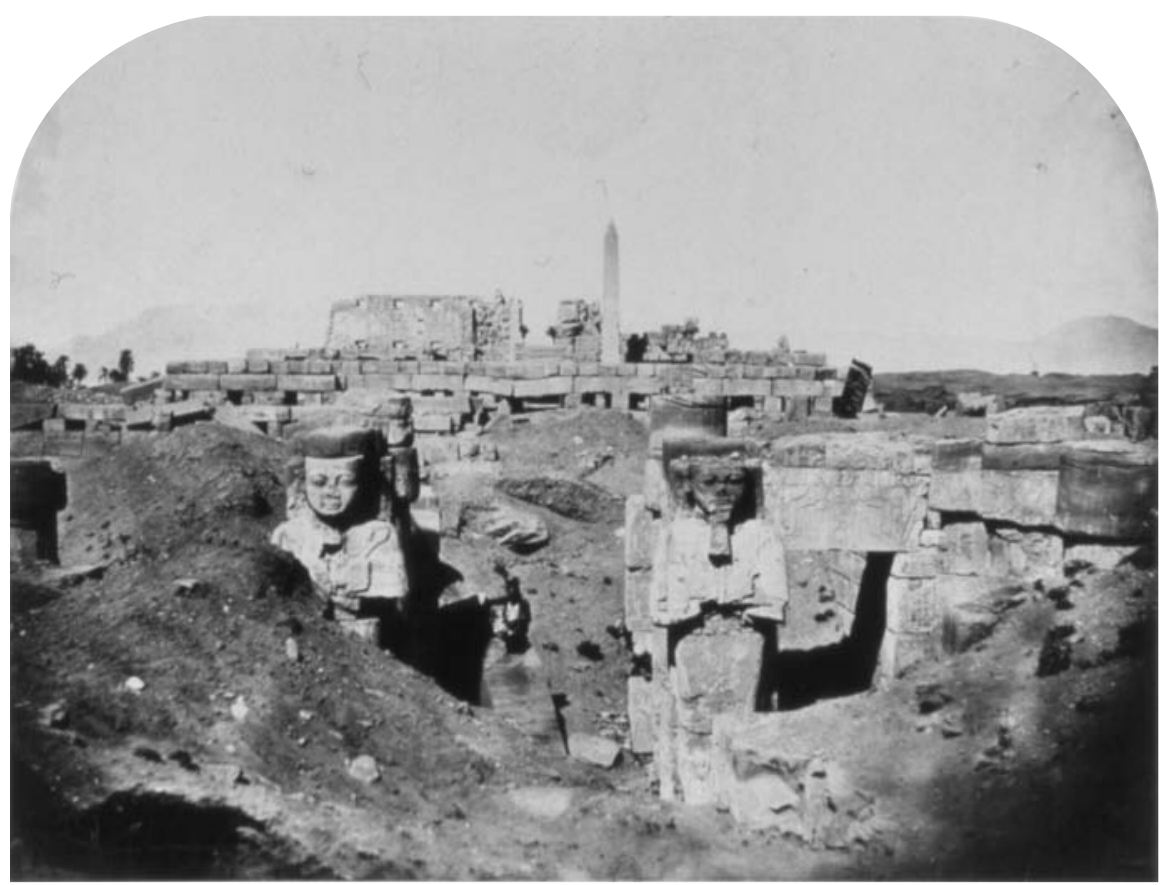

Lámina 3: Vista general de Karnac hacia 1860. Anónimo. Positivo albuminado a partir de negativo sobre cristal al colodión húmedo. $26 \times 35 \mathrm{~cm}$. Colección Prisse d Avesnes. Bibliothèque national de Francia. Département des Estampes et de la Photographie.

cunstancias bélicas. En efecto, llegó a Siria junto con las tropas imperiales que venían a responder a las masacres de cristianos en 1860 por parte de los drusos sirios. La estancia, limitada a nueve meses, explica el que Renan emprendiese excavaciones, al mismo tiempo, en cuatro lugares diferentes: Gebel-Biblos, Sidón, Amrit-Marathus y Tiro. En Amrit, donde se apreciaban en superficie los monumentos ya descritos por De Saulcy, Renan excavó durante dos meses documentando los restos mediante dibujos y fotografías. Incluso señaló la probable influencia egipcia que las estructuras y materiales descubiertos permitían vislumbrar.

La fotografía y los dibujos de la misión fueron realizados por el arquitecto Thubois. En la publicación (RENAN, 1864-1874) observamos un curioso reparto entre los alzados y reconstrucciones dibujadas y la fotografía. Las láminas representaban, mediante dibujos, los restos arquitectónicos y las reconstrucciones. Reproducían además los mapas generales con que comenzaba la explicación de cada zona geográfica. Por su parte, la fotografía estaba destinada a documentar los objetos, fuesen o no epigráficos. Los dibujos eran en ocasiones litografiados e incluso se reprodujeron mediante el oneroso procedimiento de la cromolitografía. Este hecho permite apuntar que las fotografías no se excluyeron de la publicación final, como era frecuente, por motivos presupuestarios, sino por una clara intencionalidad.
Mediante la cromolitografía se reprodujo, por ejemplo, una reconstrucción de los monumentos funerarios de Amrith a partir de un dibujo original de Thubois (RENAN, 1864-1874, vol. II, pl. $\mathrm{XI})$. Este reparto concuerda bien con la concepción de Renan en cuanto a que el arquitecto debía ayudar a hacer comprensibles los resultados y descubrimientos. La fotografía, por el contrario, los reproducía tal cual. El dibujo se adaptaba mucho más a la necesaria reconstrucción de los parciales restos (Ver Lám. 1) y, en este sentido, hacía que el lector pudiese llegar a una comprensión global de su significado histórico.

La Memoria permite observar algunos aspectos propios de la arqueología de la época como la escasa valoración del contexto de aparición de los hallazgos. Así, Thobois no consideró necesario fotografiar los objetos en el lugar original de hallazgo. En efecto, los objetos se fotografiaron como vistas "de estudio", representando así "la pieza por la pieza" fuera de su contexto, como tradicionalmente se venía haciendo.

Renan fundó la arqueología fenicia y su obra, Mission en Phénicie (RENAN, 1864-1874), fue durante 50 años el tratado de consulta "fundamental y único" sobre la materia (GranAymerich, 1998, 194). Sin embargo, buena parte de los eruditos de la época no estaban preparados para las conclusiones de Renan. En efecto, a su vuelta de Fenicia, fue elegido para la cátedra de langues hébraïques, chaldaïque et syriaque del 


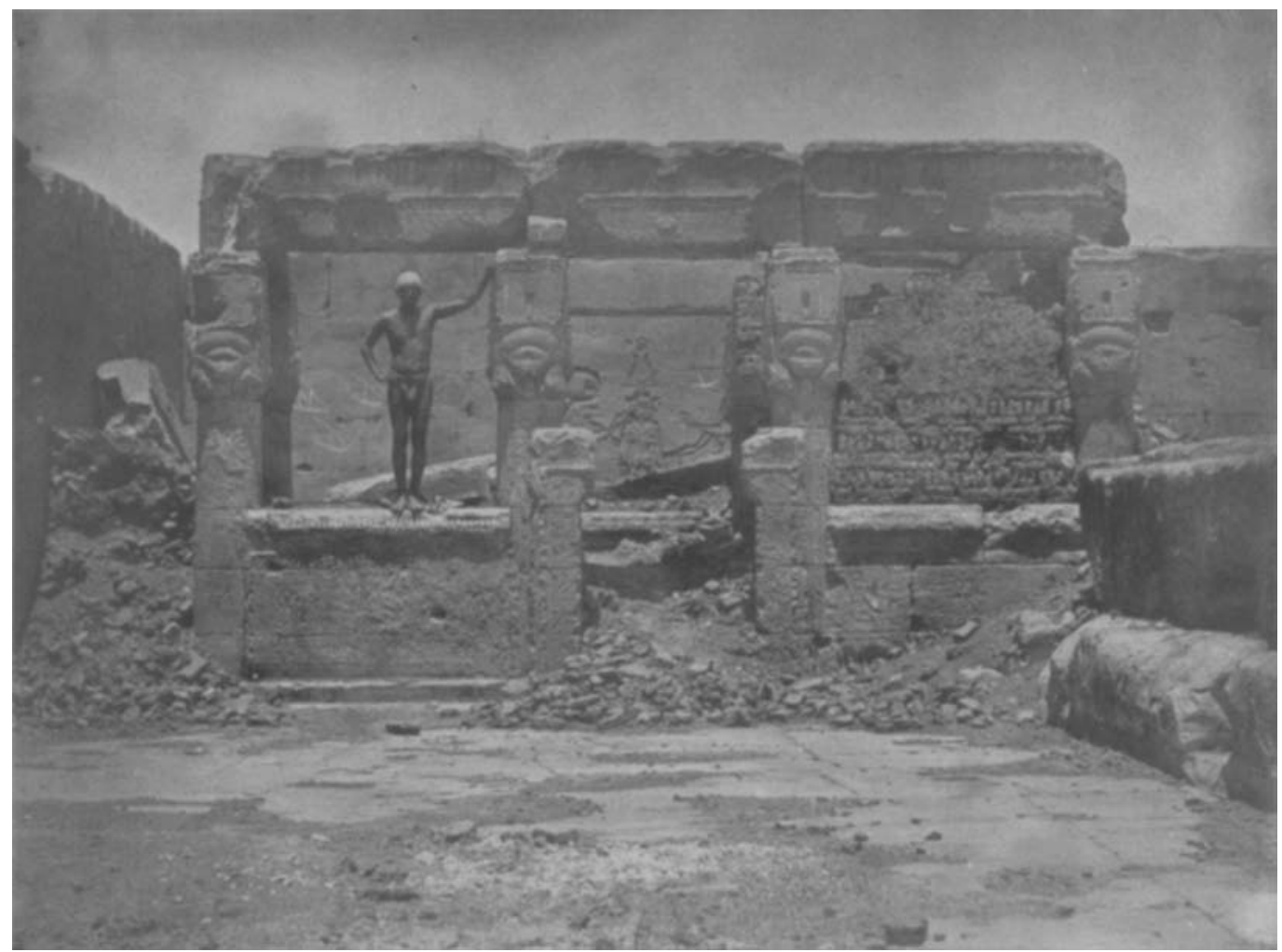

Lámina 4: Vista del Gran templo de Denderah efectuada por Maxime du Camp en 1850. Positivo en papel salado a partir de negativo de papel, 16,5 x $22 \mathrm{~cm}$. Colección Prisse d Avesnes., Bibliothèque national de Francia. Département des Estampes et de la Photographie.

Collègue de France. Cuando, el 22 de febrero de 1862 pronunció su lección de inauguración del curso sobre "el papel de los pueblos semíticos en la historia de las civilizaciones" se produjo tal polémica que el curso se suspendió (GRANAYMERICH, 1998, 194).

\section{IV-. LA INCORPORACIÓN DE LA FOTOGRA- FíA A LA ARQUEOLOGía (1875 A 1914).}

En 1870 la derrota francesa ante Prusia produjo en Francia toda una conmoción política y cultural. Se hizo célebre entonces una explicación para una derrota que conllevaba, además, la pérdida de la Alsacia y la Lorena: "no sólo nos han vencido con las armas, también con la ciencia". La derrota provocó un esfuerzo de reforma y nuevas iniciativas en cuanto a la institucionalización de la investigación arqueológica e histórica. Se contemplaba a Alemania "comme le pays où loon découvrait par la critique religieuse, par l'histoire, par la philologie, par la philosophie, les domaines prodigieuses du passé" (DIGEON, 1959, 32). Investigadores como E. Renan, G.Perrot, A.Dumont y O. Rayet, entre otros, criticaron la insuficiente organización de la ciencia francesa y la escasa financiación por parte del estado (Gran-Aymerich, 1998, 205). Este impulso de los estudios históricos abarcaba también un incremento en la atención por el propio pasado francés. Su mejor conocimiento buscaba redefinir las raíces de una patria francesa bajo la amenaza de la gran potencia prusiana y, al mismo tiempo, otorgar una mayor legitimidad al régimen contemporáneo.

En este contexto se produjo, a partir de la década de los años 70, la progresiva definición de la arqueología como una ciencia moderna. En estos años se consolidaron algunos de los principios básicos de la arqueología como la cronología comparativa enunciada y defendida, en primer lugar, por O.Montelius y Flinders Petrie. Ya en 1875, A. De Longpérier había apuntado, con ocasión de un estudio sobre las antigüedades de la isla de Santorini, el hallazgo de los mismos vasos pintados que eran usuales en las cámaras funerarias de época de Thutmosis III (DE LONGPÉRIER, 1875, 182). A partir de esta observación De Longpérier apuntaba los sincronismos entre la civilización griega y la egipcia. Esta asociación fue definitivamente enunciada por Petrie en 1891, desarrollando un método que denominó cross dating. Por su parte, A. Conze identificó el estilo geométrico en Grecia y estableció la noción de "fósil-director" en arqueología (Ver Lám. 7).

En lo que se refiere a la práctica fotográfica se produjeron también numerosos cambios. 
Durante los años finales del s. XIX se introdujeron nuevos factores como la posibilidad de fotografiar mediante placas secas. También se inventó y desarrolló un proceso eficiente de reproducción fotomecánica que multiplicó las posibilidades de la edición fotográfica. Con estas transformaciones se asistió a la emergencia de la fotografía amateur, que permitió multiplicar las aplicaciones de la fotografía y que apareciese de forma mucho más abundante en todas las esferas. Estas mejoras hicieron que tanto la toma como la reproducción de fotografías fuese más fácil y barata. Las placas secas, la fotografía estereoscópica (ver Lám. 2) y, a partir de 1889, la película de celuloide, se producían antes de la toma y se vendían preparadas para su uso, de modo que sólo quedaba insertar la placa en la cámara. La década de 1880 comenzó con la realización de fotografías al gelatino-bromuro de plata y, en 1890 se introdujo la cámara Kodak y todos los sencillos mecanismos de funcionamiento que conllevaba (NIR, 1985, 208). Estas facilidades contribuyeron a que la fotografía pasase a aprenderse en un tiempo muy escaso. Así, sabemos que Raboisson se inició en tan sólo cinco o seis lecciones durante el mes anterior de su viaje a tierra santa (NIR, 1985, 207). La mayor facilidad de las tomas fotográficas también contribuyó

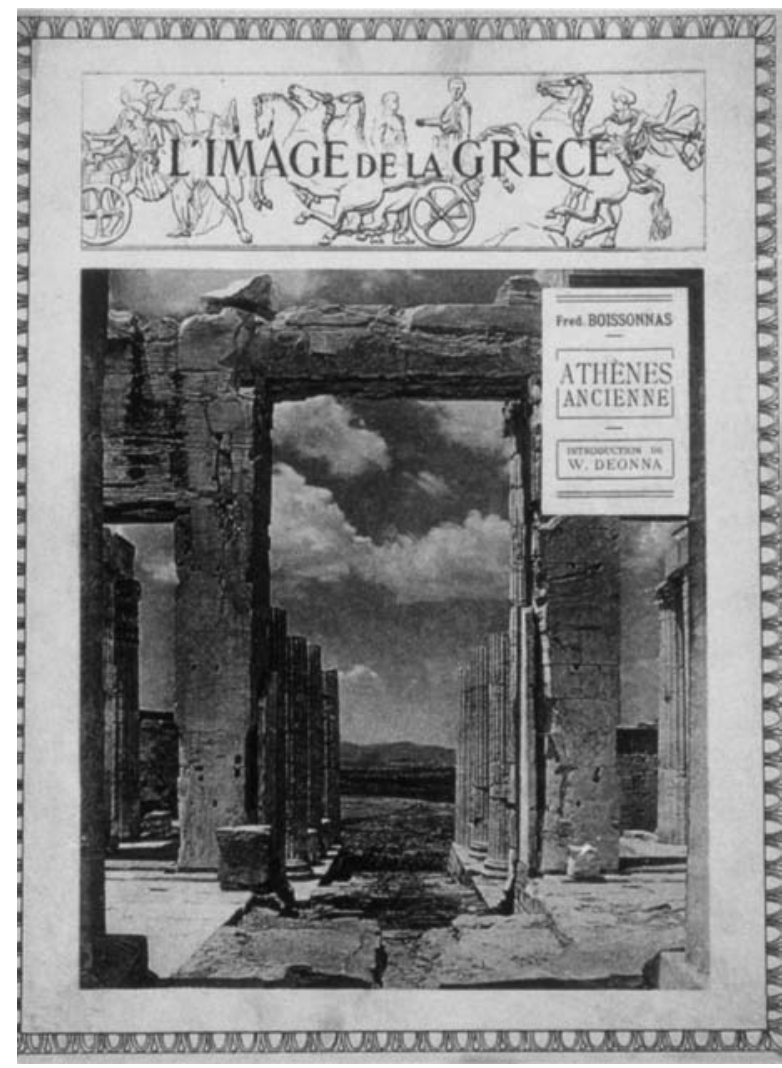

Lámina 5: Portada de la obra Images de la Grèce de W.Deonna, con la participación del fotógrafo F.Boissonas.

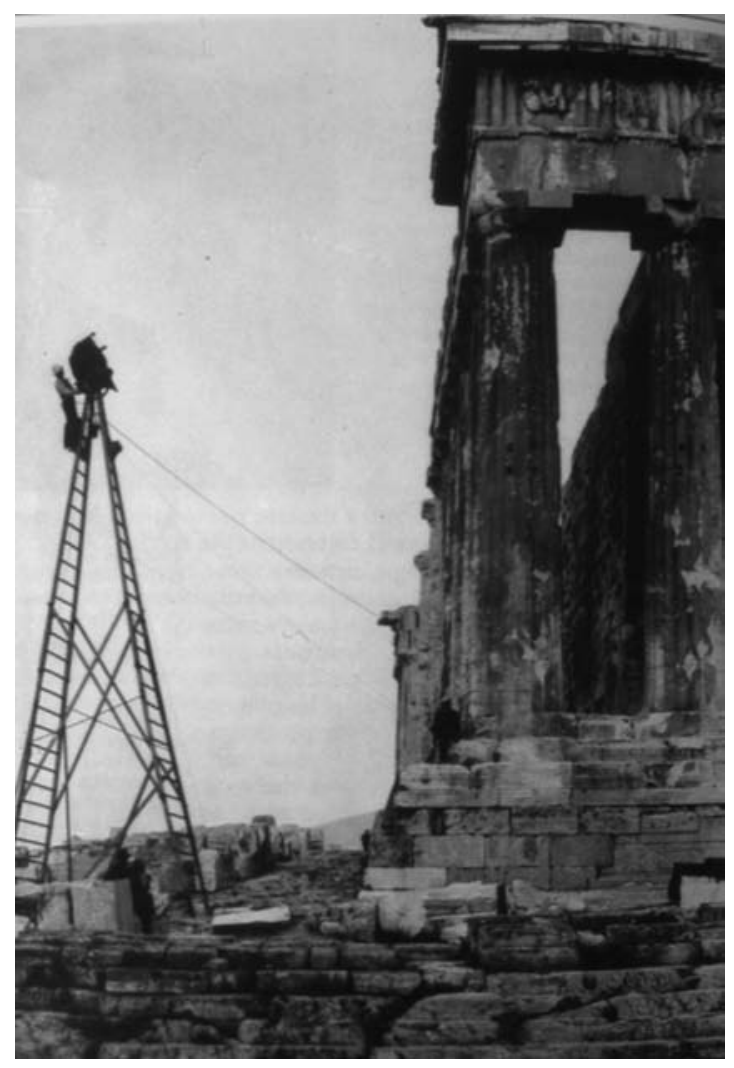

Lámina 6: El fotógrafo suizo Fred Boissonas (1858- 1946) fotografía el Partenón. En Álbumes de Grecia.

a la diversificación de sus temas. El incremento de la práctica amateur, permitió ampliar los temas representados ante la falta de obligaciones comerciales y los menores costes necesarios (NIR, 1985, 208).

Éstas son algunas de las circunstancias nos llevan a considerar la etapa que comenzó a mediados de los años 70 del s. XIX como clave en la aplicación de la fotografía a la arqueología. El cambio en el uso de la fotografía fue tanto cualitativo como cuantitativo. En efecto, hacia mediados de los años 70 del s.XIX se fueron imponiendo otras concepciones de la arqueología, cada vez más campo exclusivo de los especialistas. Además, el arqueólogo iba a poder realizar sus fotografías sin ser un experto. El menor tamaño de las cámaras, su ligereza y el menor tiempo de exposición necesario fueron, sin duda, factores que determinaron la adopción de esta técnica por parte de un mayor número de investigadores.

\section{-. Joseph Déchelette (1862- 1914).}

Entre los arqueólogos que primero incorporaron la fotografía a sus trabajos podemos destacar Joseph Déchelette (1862- 1914). A pesar de su corta carrera, ha pasado a ser conocido como "el padre de la Protohistoria francesa" ya que apor- 
tó las bases necesarias para una nueva arqueología de Europa (Olivier, 1999, 275).

Así, entre las obras de mayor repercusión durante el primer tercio del s. XX cabe citar dos significativas aportaciones de Déchelette, el Manuel d’archéologie préhistorique celtique et galloromaine (DÉCHELETTE, 1908) y Les vases ornés de la Gaule romaine: Narbonnaise, Aquitaine et Lyonnaise (DÉchelette, 1904b). Con la síntesis de los materiales ambas suponían la elaboración, por primera vez, de tipologías que permitían establecer relaciones y adscribir cronologías. Especialmente el Manuel d’archéologie préhistorique celtique et gallo-romaine tuvo una repercusión clave "formando a generaciones de arqueólogos" (DELPORTE, 1994, 3).

En la labor de Déchelette destacó su preocupación por sistematizar los objetos y crear términos para las nuevas épocas. En su opinión, la posibilidad de transmisión de la información se fundamentaba, en primer lugar, en el establecimiento de un vocabulario unificado y actualizado (Binetruy, 1994, 163). Buena parte de su actividad estuvo dedicada a la necesidad de crear estos nuevos términos para la Prehistoria. Para ello mantuvo contacto con numerosos investigadores y participó de forma activa en los debates de la época. Así, por ejemplo, sabemos por su correspondencia las ideas intercambiadas con Leite de Vasconcellos sobre una nueva terminología para la Prehistoria. En efecto, el investigador portugués le proponía, en una carta del 15 de diciembre de 1910, la utilización del nuevo término del Calcolítico: "je vous enverrai Religioes I. J'y ai proposé le terme Chalcolithique pour désigner le passage de la pierre au métal".

Por otra parte, Déchelette utilizó de forma destacada la técnica fotográfica. Diversos autores han señalado cómo fotografiaba, con el mismo talento, vasos galorromanos, sílex, o los objetos más diversos (ChÉNÉ, Foliot, RÉveILlaC, 1986, 176). Déchelette reunió una importante colección de negativos fotográficos hasta su muerte en los primeros meses de la Primera Guerra Mundial. También sabemos que generalmente asumía, durante la dirección de las excavaciones, todo el registro fotográfico (CHÉnÉ, Foliot, RÉveILLAC, 1986). Por este motivo sus fotografías son especialmente ilustrativas de los objetivos y la intencionalidad del autor. Sin embargo, la documentación disponible se restringe hoy casi únicamente a la que el investigador publicó en su día. También conocemos, por ejemplo, que el investigador realizó fotografías aéreas a principios de siglo a partir de un globo, custodiadas hoy en el Museo de Roanne (Francia).
En cuanto a la arqueología de campo destaca su actividad en el yacimiento de Bibracte. El oppidum de la Borgoña había sido explorado y excavado anteriormente bajo la dirección de J. G. Bulliot (1899). Su trabajo carecía de plantas de la excavación y de una síntesis histórica completa. En resumen se trataba, más bien, de una lista y descripción de los descubrimientos que se habían sucedido en las diferentes campañas (BINETRUY, 1994, 90). Frente a este panorama de investigaciones en el yacimiento, Déchelette introdujo cambios fundamentales. Aparecidas en 1904, sus Comptes Rendus supusieron un acercamiento diferente al yacimiento, dejando de lado las aún frecuentes evocaciones literarias a los galos por unos intentos de clasificación científica.

Por primera vez, se fotografiaron las estructuras descubiertas en el transcurso de la excavación (Binetruy, 1993, 93). De una forma aún novedosa en la época, Déchelette fotografiaba los diferentes objetos en su contexto de descubrimiento. Al publicar las excavaciones de Bibracte (DÉCHELETTE, 1904a) el investigador francés creyó necesario incluir láminas que ilustrasen, fotográficamente, las excavaciones llevadas a cabo. Observamos, en este sentido, una significativa evolución respecto a otras utilizaciones más usuales hasta el momento: Déchelette no utilizaba la fotografía para ilustrar los objetos más significativos que se habían descubierto, sino las estructuras del oppidum.

Estas fotografías constituían, en su opinión, "documentos nuevos". Frente a una documentación que había atendido, fundamentalmente, a las esculturas y piezas deslumbrantes -"hasta hoy los objetos muebles habían tenido los honores de la reproducción"-, Déchelette abordó otro uso. $\mathrm{El}$ investigador ilustraba estructuras "en las que la rusticidad del aparejo así como la ausencia de toda moldura o escultura imprimen un carácter muy diferente que el de las construcciones galoromanas más recientes" (DÉCHELETTE, 1904a, 3). En su opinión los arqueólogos debían "conceder los mismos privilegios a las estructuras" (DÉCHeleTte, 1904a, 4) que a los objetos prestigiosos o llamativos. Además, las estructuras descubiertas parecían tanto más importantes en cuanto que constituían, en su opinión, "las muestras más antiguas de la arquitectura civil en el suelo de la Galia" (DÉChelette, 1904a, 4).

De sus trabajos se desprende la noción de la fotografía como un documento irreemplazable, como un medio de preservar lo que la excavación hacía desaparecer. Particularmente se refirió a las estructuras descubiertas: Mediante la imagen fotográfica guardaba testimonio de unas estructuras que "sont remblayés au fur et à mesu- 
re des travaux" (DÉchelette, 1904a, 4). Además, la rapidez del registro fotográfico se adaptaba bien al ritmo de la excavación arqueológica. El dibujo, mucho más lento, suponía una mayor paralización y demora en los trabajos.

Además, el investigador otorgó a la fotografía un uso científico, incluyéndola sin reservas en el discurso arqueológico. De esta forma, implicaba el registro fotográfico en el discurso, en las teorías defendidas y la reconstrucción histórica del yacimiento. Así, en la explicación de los resultados de las campañas se recurría a las fotografías como comprobación: "las excavaciones de 1898, de las que la lámina I proporciona una vista de conjunto, nos dieron la solución al problema. Nos encontrábamos en presencia de un gran taller de forja" (DÉCHELETTE, 1904a, 13). Déchelette aludía también a las figuras al describir los resultados de áreas más restringidas. Así, por ejemplo, la casa PCO 2 se describía apoyándose en dos figuras de la parte gráfica. En la lámina IV una fotografía ilustraba el transcurso de la excavación en esta casa, mientras que la IX facilitaba un dibujo de su planta.

En su obra la fotografía era el referente para corroborar cualquier dato. En efecto, en su trabajo encontramos observaciones interesantes invitando al lector a que las comprobase en las fotografías. Por ejemplo, remitía a dos láminas para comprobar una estructura que estaba describiendo: "on distingue nettement l'entrée du fourneau, avec son arc en brique, sur la planche $\mathrm{V}$ (partie gauche) et sur la planche VI (partie droite)" (DÉCHELETTE, 1904a, 39, nota 1).

El uso "moderno" de la fotografía en Déchelette se manifiesta además en la progresiva desaparición de personajes o útiles en la excavación, frecuentes en las fotografías del s. XIX. El protohistoriador francés mostró su interés por registrar -y ofrecer al lector- un panorama de aspectos diferentes como los perfiles y las áreas excavadas en detalle. Especialmente interesante nos resulta el "reparto" de la representación gráfica mediante el dibujo y la fotografía. Así, mientras que el dibujo se reservó generalmente a los materiales, la fotografía estuvo destinada, fundamentalmente, a las vistas generales o a ilustrar los objetos en su contexto originario de hallazgo. $\mathrm{Su}$ uso de la parte gráfica de una obra se extendía también a los croquis, como en los estudios de fíbulas (DÉcheleTTE, 1904a, 40), las tablas, los planos con diversas anotaciones, etc. (BINETRUY, 1994, 93).

Déchelette clasificaba, comparaba y ordenaba con la finalidad de elaborar novedosas teorías. Agrupadas en láminas, clasificadas por tipos, defi- nidas sus pastas y colores, abordó importantes clasificaciones cerámicas. En una de sus obras más significativas, el Manuel d archéologie préhistorique celtique et gallo-romaine, Déchelette se preocupó de reunir la documentación gráfica necesaria gracias a los contactos con numerosos colegas, a los que pidió la mayoría de las 250 ilustraciones finales. En la mayoría de los casos, se recurrió a investigadores como Piette, Mortillet y Cartailhac, a revistas francesas o extranjeras. En la edición se preferenció, por lo general, el dibujo frente a las fotografías ya que, además del menor coste, suponían una mayor claridad.

Al tanto de los descubrimientos que se iban sucediendo en diferentes países de Europa, Déchelette mantuvo contacto con algunas de las personalidades más significativas dentro de la arqueología de la Península Ibérica. Además de conocer las novedades de la protohistoria peninsular, Déchelette intervino activamente en su definición y estudio a raíz del consejo de Cartailhac. El prehistoriador francés le introdujo al problema que planteaban las necrópolis que el Marqués de Cerralbo estaba documentando en Soria y Guadalajara. Su interés por los descubrimientos que se estaban realizando en esos años le llevó a viajar a España en 1911. Durante esta estancia visitó, en coche y a caballo, varias excavaciones así como los museos de Gerona, Ampurias, Zaragoza y Toledo. El investigador francés aprovechó esta estancia para conocer de primera mano las colecciones del Marqués de Cerralbo, colaborando incluso en su clasificación ( Binetruy, 1994, 162). Como consecuencia de esta buena relación Déchelette leería, el 30 de agosto de 1912 y con el permiso del Marqués, "Les fouilles du marquis de Cerralbo" ante el Institut de France (París).

El investigador francés también participó en algunos de los debates más importantes de la arqueología protohistórica del momento, como la adscripción cronológica de la cerámica ibérica. En este sentido Déchelette defendió la postura esgrimida por L. Siret frente a la de P.Paris. Frente a la consideración de Paris de una cerámica ibérica relacionada con paralelos micénicos, el investigador belga esgrimió sus observaciones estratigráficas de Villaricos (Almería) así como el conocimiento tras los resultados de las excavaciones de Cartago. En estos yacimientos, el hallazgo de piezas griegas junto a las debatidas cerámicas ibéricas permitía, como señaló Siret, establecer paralelos y procedencias más próximas cronológicamente.

En los años siguientes y mientras que algunos investigadores defendieron las posturas de Paris, otros optaron por la de Siret. En este sentido des- 
tacó Déchelette, quien hizo interesantes precisiones fijando la cronología de Villaricos en torno al siglo $\mathrm{V}$ a.C. El investigador francés se apoyaba en el hallazgo de cerámicas griegas en el yacimiento almeriense. Déchelette señaló la semejanza entre los materiales ibéricos de yacimientos como Villaricos, Meca y El Amarejo (DÉCHelette, 1909, 17) yacimiento éste último donde P.Paris había recogido fragmentos de vasos griegos (BRONCANO, BLÁNQUEZ, 1985; Pereira, 1987, 21). Sus aportaciones sobre la Protohistoria peninsular motivaron su elección como Correspondiente de la Real Academia de la Historia de Madrid el 25 de junio de 1910 (BINETRUy, 1994, 153).

\section{IV.1. La época de las grandes misiones.}

El último tercio del s. XIX estuvo caracterizado por la multiplicación de las excavaciones llevadas a cabo por las Escuelas extranjeras de arqueología en lugares como Grecia, Oriente Próximo y Egipto. En estos momentos se estableció una "geografía" o reparto de las excavaciones que, salvo escasas excepciones, ha continuado hasta hoy. Concretamente, Francia desarrolló sus trabajos en lugares como Thasos, Delos, Delfos, y Argos. Estos lugares por explorar se eligieron sobre todo siguiendo los textos clásicos y según los datos que proporcionaba la epigrafía. Esto provocó que las principales excavaciones se efectuasen muchas veces en santuarios, como Epidauro, Samos, Olimpia, Samotracia, etc. La aplicación de la fotografía no se realizó de una manera uniforme ni general. Así, entre las publicaciones de expediciones que continuaron sin incluir la fotografía podemos destacar la de las excavaciones de Asia Menor, durante 1872-1873. Entre estas actuaciones destacan las del teatro de Mileto, el ágora de Latmos y el templo de Apolo en Dydimes.

A pesar de esto, la aplicación de la fotografía en las investigaciones y publicaciones arqueológicas comenzó a generalizarse a final del período. Francia desarrolló, entre los últimos años del s. XIX y los primeros del XX, una serie de campañas en Tello, la antigua Lagash. Los encargados de realizar la parte fotográfica y de trazar los mapas fueron H. de Sevelinges y E. de Sarzec. La primera publicación sobre estas campañas utilizaba la fotografía en la reproducción de los objetos más destacables o sorprendentes. Destacamos especialmente el que la fotografía se utilizase en la reproducción de algunas de las estructuras descubiertas en la excavación (SARZeC, HeuzeY, 1884-1912). En la obra apareció una de las innovaciones fundamentales de la época; la mayor aparición de fotografías ilustrando el contexto de los hallazgos arqueológicos. En el texto se aludía a estas "vistas fotográficas de las construcciones descubiertas en las excavaciones".

E. de Sarzec (1832-1901), quien acometió la realización de buena parte de las fotografías, fue cónsul de Francia en diversos lugares de Oriente Próximo. Aunque carecía de una formación arqueológica, se dio cuenta de la importancia de las excavaciones continuadas y de prestar atención y recoger todos los objetos de pequeño tamaño. En este sentido y frente al mayor interés de la época por las tablillas y la epigrafía, Sarzec realizó una cuidadosa aproximación, innovadora en la época. El éxito de la misión se vio corroborado al encontrarse, durante los trabajos en Tello, los archivos reales de Lagash. Estas excavaciones contribuyeron a probar, científicamente, la existencia de una civilización sumeria que, por los restos aparecidos, aparecía como la sociedad de organización estatal más antigua que se conocía.

En las posteriores publicaciones de la misión francesa de 1903 sobre Tello (Lagash) encontramos, junto a los habituales dibujos, el uso de la documentación fotográfica. Los negativos, reproducidas por medio de la heliografía Dujardin, se dedicaron sobre todo a los diferentes objetos (CROS, HEUZEY, Thureau-DANGin, 1914, 9). Sin embargo, también se percibe en la publicación final de 1914 una mayor preocupación estratigráfica que se plasmó en la descripción de trincheras y en las frecuentes alusiones a las estratigrafías. En efecto, en Nouvelles fouilles de Tello, Mission Française en Chaldée (CROS, Heuzey, Thureau-Dangin, 1914) se aprecian descripciones con alusiones a las láminas fotográficas como "por encima del otro enlosado, en una tierra cenicienta, de tierra batida enrojecida por el fuego, a $50 \mathrm{~cm}$. de profundidad y a cuatro metros de la puerta, por 20 grados, se encontraba la escultura en diorita de color verde (ver Pl. I y pp. 21)". Resulta interesante, no obstante, cómo se prefirió, al realizar la fotografía de la citada pieza, presentarla como un objeto de arte, fuera del contexto originario de su hallazgo. A pesar de la cuidada descripción que hemos mencionado, lo realmente importante era la representación de la pieza. Sólo dos, de entre las once láminas existentes, se dedicaron a ilustrar las estructuras descubiertas (figs. 5 y 6). Tomadas por el mismo Gros, representaban una panorámica general de la excavación y un detalle del recinto funerario.

Sin duda una de las misiones francesas más conocidas fue la Grande Fouille de Delfos, llevada a cabo entre 1892 y 1903. Para la consecución de este proyecto fue clave la acción de Théophile Homolle (1848-1925), nombrado en 1890 director de la École Françise de Atenas. A 
partir de ese momento estuvo encargado, fundamentalmente, de incrementar la actividad arqueológica francesa en el Mediterráneo y de consolidar las excavaciones francesas en Delfos, entonces en disputa entre los investigadores alemanes y los franceses.

En 1840 Ottfried Müller había sido el primero en excavar en la localidad de Delfos. Durante estos trabajos descubrió el extremo oriental del gran muro poligonal que se había construido para sostener la terraza del templo de Apolo y que aparecía cubierto de documentos epigráficos. Entre 1860 y 1861 Paul Foucart también había conseguido reunir más de 500 inscripciones procedentes de este lugar. Finalmente, en 1887, Francia consiguió el monopolio de las excavaciones en Delfos durante diez años, concretamente hasta 1903. A partir de entonces Th. Homolle comenzó a organizar su equipo para iniciar las excavaciones. Resulta destacable cómo concedió la dirección técnica de los trabajos a Henry Convert, ingeniero de Puentes y Caminos y destacado dibujante y fotógrafo. Igualmente recurrió a un arquitecto para levantar las plantas, alzados y reconstrucciones, por lo que incorporó en este equipo al arquitecto $\mathrm{A}$. Tournaire. Estas elecciones representaron también evidentes ventajas en la infraestructura del yacimiento. En efecto, Convert instaló muy pronto un sistema de vagones que facilitó el necesario desescombrado del yacimiento. La fotografía estuvo presente, desde el primer momento, en la organización de una empresa capital para la arqueología francesa de la zona como fue la Grande Fouille de Delfos.

\section{Características de la Aplicación de LA FOTOGRAFía A LA ARQUEOLOGÍA EN Francia.}

\section{V.1. La confianza en el registro fotográfico: la ima- gen fotográfica como reflejo veraz de la realidad.}

Durante buena parte del s. XIX se pensó que el registro fotográfico reproducía la realidad tal cual era. El registro mecánico de la fotografía reproducía lo real sin intervención alguna por parte del fotógrafo. Lo que se veía en el daguerrotipo o en el calotipo era "la realidad" (CLARKE, 1997, 45). Esta aparente objetividad impulsó que científicos y eruditos de todas las áreas se interesaran, desde momentos muy tempranos, por este nuevo meca- nismo de reproducción. En este sentido, los arqueólogos franceses del siglo XIX pronto le atribuyeron virtudes como la de constituir un "témoin incorruptible" que ofrecía representaciones "inécusables" y "mathématiquement exactes" 2 (FEYLER, 1993, 189). La precisión del mecanismo fotográfico fue también uno de los criterios fundamentales al juzgar el nuevo procedimiento. Así, la reproducción del más ínfimo detalle se constataba con gran alegría; era un dato más que garantizaba su autenticidad (STARL, 1994, 34). Así, y a partir de 1854, la fotografía de gran formato se convirtió en un útil indispensable para la reproducción fiel (CHLUMSKY, 1999, 85).

En 1851 el crítico Francis Wey presentaba las fotografías como la perfecta representación de toda obra y, en cualquier caso, preferible a los otros medios de representación: "Une médiocre épreuve héliographique du portail de Chartres ou de Bourges sera toujours préférable, et comme fini, et comme réalité, et comme relief, et comme précision, à la gravure la plus accomplie. Dans toutes sortes des sujets, la reproduction plastique est tout et la photographie en est la perfection idéale" (WEY, 1851). En esta opinión del crítico francés se aprecia la confianza concedida en el s.XIX a los medios que parecían "científicos" o "mecánicos" y la alta valoración del detallismo del procedimiento fotográfico.

También el arquitecto Viollet-le-Duc utilizó la fotografía como una técnica auxiliar para la arquitectura. En 1853 apareció, editada por Lemercier y por Morel, la Monographie de NotreDame de Paris et de la nouvelle sacristie de Lassus et Viollet-le-Duc, ilustrada con 12 fotografías (Foliot, 1986, 37). El conocido arquitecto se había interesado desde muy pronto por esta técnica. Ya en 1842 había encargado a Lerebours una serie de daguerrotipos de la catedral de París, antes de emprender su restauración (Foliot, 1986, 37). En este sentido resulta significativo que, en su Dictionnaire raisonné de l Architecture française (1854) Viollet-le-Duc rindiese un sincero homenaje a la fotografía. Ésta -escribía- "présente cet avantage de dresser des procès-verbaux irrécusables et des documents que l'on peut sans cesse consulter, même lorsque les restaurations masquent des traces laissées par la ruine. Dans les restaurations, on ne saurait donc trop user de la photographie, car bien souvent on découvre sur une épreuve ce que l'on n'avait pas aperçu sur le monument lui-même" (CHRIST, 1980, 3). 
Este testimonio parece corroborar que el conocido arquitecto concibió la fotografía como una importante auxiliar de la arquitectura (CHRIST, 1980, 3). Viollet-le-Duc no podía imaginarse que los "procès verbaux irrécusables" delatarían un día ciertos aspectos de su trabajo. En efecto, al observar negativos como los de Mestral sobre St. Cernin de Toulouse, podemos valorar hasta qué punto el arquitecto se dejó llevar, en su restauración arquitectónica, por algunas ideas que acabaron por transformar y alejar al monumento de su apariencia original (FOLIOT, 1986, 38).

También el viaje efectuado por Maxime du Camp y Flaubert a Egipto nos proporciona valiosos testimonios sobre la consideración de la fotografía. Con motivo de esta expedición la Académie des Incriptions et Belles-Lettres redactó una serie de normas u obligaciones indicativas de las esperanzas que sus miembros habían depositado en la fotografía. Así, en el Rapport de la Comisión nommée par $l$ Académie des Inscriptions pour rédiger les instructions du voyage de Máxime du Camp (1849) se indica cómo el objetivo de la cámara era obtener vistas de los monumentos y copias de las inscripciones (Dewachter, OSter, 1987, 14). El aparato fotográfico aparecía como un nuevo compañero del viajero; hábil, rápido y siempre escrupulosamente fiel. Los resultados que Du Camp iba a obtener "serían de interés para la filología, la arqueología y el arte". En efecto, "aunque los principales monumentos de las orillas han sido dibujados, será útil poseer varias vistas de conjunto tomadas a la Daguerrotipia y detalles de arquitectura, ambas en grandes proporciones”. El carácter particular de la fotografía, su exactitud incontestable y su minuciosa fidelidad daban un nuevo valor a las vistas que obtenía (Dewachter, Oster, 1987, 14).

Algunas de estas indicaciones muestran cómo la mission había sido encargada por un organismo científico. En efecto, la Académie deseaba que los resultados de este viaje sirviesen para las investigaciones sobre Egipto. En este sentido, debía procurar, siempre que fuese posible, completar las vistas generales de los monumentos con otras más detalladas. Sobre todo debía evitar la dispersión y la costumbre -abundante entre los viajeros- de pasar de un monumento a otro antes de agotar las posibilidades que cada uno le ofrecía (Dewachter, Oster, 1987, 14). Esta observación permite acercarnos a la opinión que los miembros de la Academia tenían sobre la fotografía de viajeros, que no colmaría su curiosidad ni su necesidad de conocer en profundidad determinados monumentos. Ésta podría haber sido, sin duda, una de sus motivaciones principales para financiar el nuevo viaje de Du Camp a
Egipto. Ejemplar de estos objetivos científicos de la Académie resulta el comentario "Il ne śagit plus de charmer nos yeux par les effets séduisants que la lumière porte dans la chambre noire, mais de copier fidèlement et avec suite, des textes reclamés par la science" (DEwachter, Oster, 1987, 14). La cámara y Du Camp se convertían, así, en instrumentos para una ciencia que reclamaba nuevos textos epigráficos y datos arqueológicos fiables (Ver Lám. 4). Con esta misión se proponían reunir la documentación necesaria para los estudios científicos: unas fotografías sin efectos estéticos, realizadas de cara a convertirse en un instrumento de primera mano de cara a investigaciones epigráficas o históricas.

La publicación del viaje a Egipto de Flaubert y Du Camp -Égypte, Nubie, Palestine et Syrie, dessins photographiques recueillis par M. Du Camp, format petit in-folio- tuvo una acogida favorable por parte de los medios científicos. Así, la Revue Archéologique señaló cómo "muchas publicaciones se han hecho sobre el antiguo Egipto y todo el mundo sabe apreciar el interés que ofrecen los monumentos que cubren su suelo. A pesar del número de publicaciones (...) creemos poder afirmar que ésta que anunciamos hoy está llamada a buen éxito, puesto que se presenta bajo un aspecto novedoso y será muy apreciada por todas las personas que conceden mucha importancia a la más escrupulosa exactitud en la representación de los monumentos, a una perfección a la que no pueden llegar el grabador o el litógrafo, sea cual sea su talento" (VVAA., 1852, 192). La Revue Archéologique sentenciaba "sólo la fotografía consigue reproducir hasta en los más mínimos detalles todo conservando el aspecto general del conjunto" (VVAA., 1852, 192). La fotografía proporcionó además una calidad nueva a la imagen. Esto permitió obtener, muchas veces por primera vez, valiosos datos respecto al envejecimiento de la piedra o la conservación de los edificios. También permitió estudiar aspectos ignorados hasta entonces. De nuevo el testimonio de Ernest Lacan resulta ilustrativo en este sentido: "Il y a, aux corniches les plus élevées des cathédrales, dans les galeries où l'hirondelle et le corbeau font leur nid, des figures de saints ou des vierges que nul oeil humain n'a jamais pu contempler de près et que l'objectif découvre et reproduit dans toute leur suavité de formes et attitude" (JAMmES, 1981, 70).

Ya en el siglo XX, la confianza de los arqueólogos en el registro fotográfico siguió siendo bastante usual. En efecto, W. Deonna señalaba en los años 20 cómo la fotografía proporcionaba al erudito la posibilidad de contemplar, en la tranquilidad de su gabinete, los resultados de las investigaciones sobre el terreno. De esta forma, 


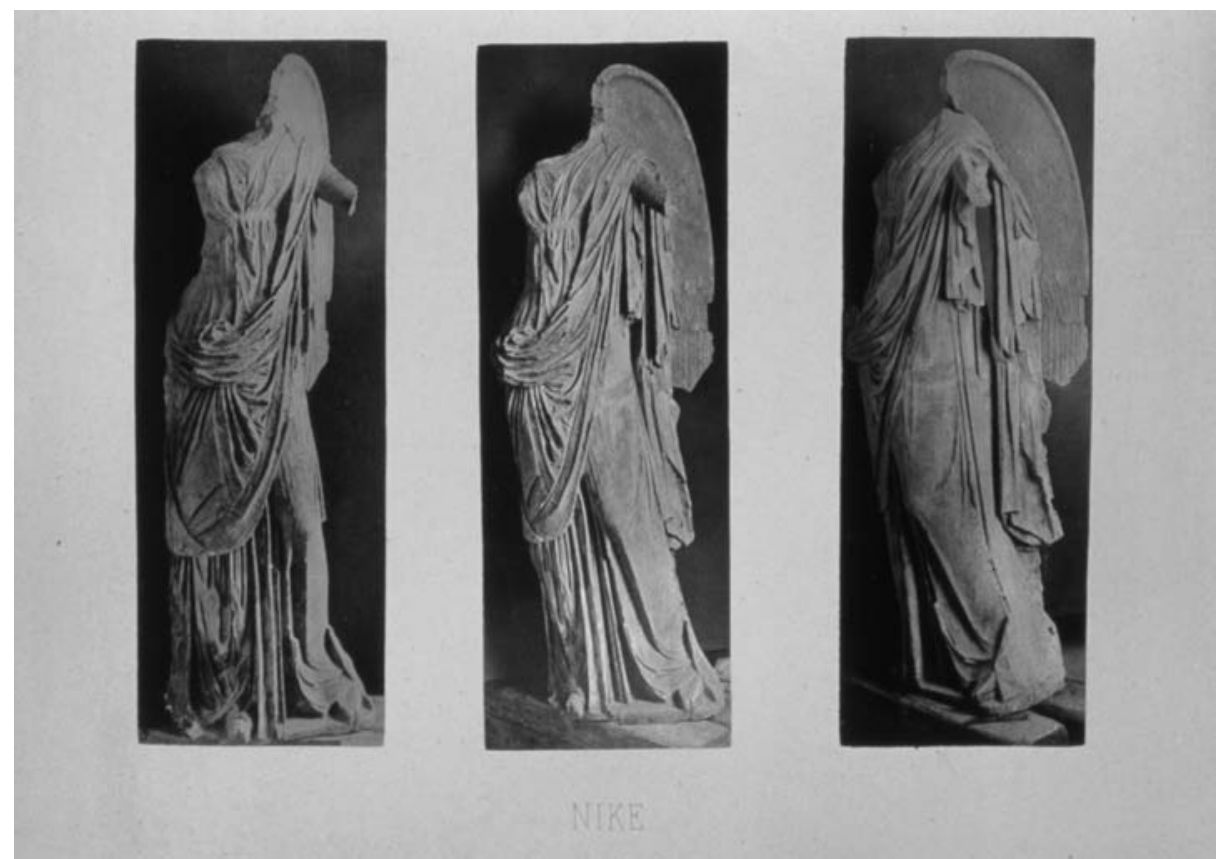

Lámina 7: Vista, desde varias perspectivas, de una Niké encontrada durante las excavaciones de A.Conze en Samotracia (18751880). En Archaologische Untersuchungen auf Samohtrake, Viena.

la actividad arqueológica de nuevo bajo sus ojos (DEONNA, 1922, 85). El arqueólogo suizo seguía expresando la idea de que la fotografía proporcionaba una imagen fiel y veraz (Ver Lám. 5). Constituía, además, una fuente de primer orden para conocer el aspecto primitivo de ciertos edificios antes de que las restauraciones, destrucciones o limpiezas los alterasen (DEONNA, 1922, 85). En efecto, "mediante la fotografía, el pasado se vuelve vivo" (DEONNA, 1922, 86).

A pesar de esta confianza en las capacidades del registro fotográfico, Deonna llamó la atención sobre los riesgos que su uso conllevaba. El autor parecía ser consciente de los falseamientos que podía introducir y de los errores posibles para la investigación histórica. En efecto, factores como el mayor o menor alejamiento, la iluminación, etc. hacían surgir diferencias notables entre varias fotografías de un mismo objeto. El arqueólogo, "encontrando en la reproducción mecánica mediante la fotografía una ayuda preciosa, no debe olvidar estas causas posibles de error" (Deonna, 1922, 93). Dicho investigador parece considerar necesario recordar este aspecto a los arqueólogos de su época. Esto nos hace pensar que la mayoría seguía considerando que la fotografía les proporcionaba un testimonio objetivo, restituyendo el pasado tal cual había sido.

Teniendo en cuenta esta percepción de la fotografía no resulta extraño que muchos arqueológos considerasen que su uso en arqueología conseguía "que l'archéologue puisse emporter avec lui à loisir une représentation absolument exacte du sujet douteux" (Foliot, 1986, 131). Esta percepción nos lleva a considerar los planteamientos positivistas, su protagonismo en la ciencia arqueológica a partir del último tercio del s. XIX y la adecuación de la técnica fotográfica a sus planteamientos.

\section{V.2. La Fotografía y el Positivismo.}

En Die Photographie Siegfried Kracauer utilizó la fotografía para explicar y criticar el historicismo alemán (KRACAUER, 1927). El autor volvió a insistir en las relaciones entre ambos aspectos unos 40 años después, en su obra póstuma History: things before the Last (KRACAUER, 1967). Kracauer llamó la atención sobre el hecho de que Daguerre era contemporáneo de uno de los máximos ideólogos del historicismo, Leopold Von Ranke (1795-1886). Constató, además, cómo la voluntad de éste último había sido lograr transmitir los hechos tels qú ils ont été -wie es eigentlich gewesen. Este objetivo de Ranke se adecuaba a la manera en que la fotografía transcribe la realidad (About, ChÉroux, 2002，10). Significativamente, también Auguste Comte iba a desarrollar sus principales ideas en la misma época que el mundo pasaba a conocer el invento de Daguerre (Clarke 1997, 45).

La fotografía se adaptaba perfectamente a la búsqueda del dato clasificatorio y sistematizador de los planteamientos positivistas. Uno de los textos programáticos de la denominada escuela 
metódica fue escrito por G. Monod en 1876 y se editó con motivo del primer número de la Revue Historique. Frente a la metafísica y las elucubraciones de parte de la ciencia anterior, la fotografía parecía encarnar la pretendida objetividad científica del dato demandado por la ciencia positivista.

La escuela metódica intentó alejar la investigación histórica de toda especulación filosófica (Bourdé, Martin, 1983, 137). Mediante la aplicación de técnicas que se consideraban rigurosas, los investigadores intentaban llegar a una objetividad histórica absoluta. Teóricamente habría estado influida por las aportaciones de Augusto Comte. Una de sus formulaciones más conocidas la realizó L.Bourdeau en L' histoire et les Historiens; essai critique sur lhistoire considérée comme science positive (1888). Estos historiadores pertenecieron a la generación que aplicó las reformas de la enseñanza superior en Francia tras la derrota frente a Prusia de 1870. A partir de esta época, el dominio o preponderancia del positivismo habría continuado hasta 1940 aproximadamente.

Además de la influencia de Comte habría que considerar la importante influencia de Leopold von Ranke en los historiadores franceses del período 1880-1930. Esta influencia estuvo facilitada por las estancias que éstos últimos llevaron a cabo en las universidades alemanas, especialmente a partir de 1870. Desde mediados del s. XIX las teorías de Ranke pusieron en cuestión las filosofías de la historia, que el autor caracterizaba de especulativas, subjetivas y moralizantes. Frente a este panorama, Ranke propuso la adopción de fórmulas más científicas para llegar al conocimiento histórico, más objetivas o "positivas". Sus planteamientos influyeron en varias generaciones de historiadores, primero en Alemania y después en Francia. Entre los principales postulados teóricos de Ranke destacaríamos:

-. Los historiadores no deben juzgar el pasado ni intentar modificar la opinión de sus contemporáneos, sólo contar lo que realmente sucedió.

-. No debía existir ninguna interdependencia entre el historiador y el hecho histórico. El historiador debía escapar a todo condicionamiento social para intentar ser lo más imparcial posible ante los acontecimientos.

-. La historia -como conjunto de res gestaeexiste en sí misma, es objetiva. Incluso puede decirse que tiene una forma determinada, una estructura que es accesible al conocimiento, que es aprehensible por parte del historiador.

-. La relación cognitiva se realiza a través de un modelo de tipo mecanicista. El historiador debe registrar el hecho histórico de una forma pasiva, "comme le miroir reflète l'image d'un objet, comme l'appareil photographique fixe l'aspect d'une scène" (Bourde, Martin, 1983, 164).

-. La labor del historiador consiste en reunir el suficiente número de datos, sirviéndose para ello de documentos seguros. A partir de estos hechos, la narración histórica se organiza por sí misma y se deja interpretar.

Dentro de estos planteamientos, toda reflexión teórica parecía inútil, incluso perjudicial, puesto que introducía en el proceso elementos de especulación. Según Ranke, la ciencia positiva podía llegar a la objetividad y al conocimiento de la realidad histórica. La escuela metódica en Francia (1880-1930) aplicó los principios de Ranke. En este sentido, G. Monod declaraba la neutralidad del historiador "le point de vue strictement scientifique auquel nous nous plaçons suffira de donner à notre recueil l'unité de ton et de caractère" (Bourde, MARTIN, 1983, 164).

La adopción de la fotografía se aceleró en estos años y se adaptó a los requerimientos de la escuela metódica y, concretamente, a su incorporación de técnicas que se creían objetivas. Sus características concordaban, perfectamente, con estas exigencias planteadas por las nuevas corrientes teóricas y por la ciencia alemana. Concebida como una analogía de la realidad, se adecuaba perfectamente al desarrollo de investigaciones basadas en estos planteamientos. La fotografía significaba entonces una forma de poseer el objeto, siendo susceptible, a continuación, de todo tipo de estudios. Su rápida incorporación se comprende además dentro del proceso, característico del s. XIX, respecto a la clasificación como primer paso del conocimiento científico.

Esta adecuación de la fotografía a las exigencias de la ciencia del s. XIX se había señalado desde el discurso pronunciado por F. Arago por el que se dio a conocer la invención de la fotografía (19 de agosto de 1839). Los argumentos expuestos por Arago llamaban la atención sobre la utilidad del nuevo descubrimiento. Su intervención tenía como objetivo, en primer lugar, crear una "émotion nationale" (BRUNET, 2000, 111) que produjera la aceptación unánime del nuevo invento, evitando las reticencias de la Académie des Beaux-Arts (Brunet, 2000, 111). El texto del discurso insistía especialmente en la demostración de la utilidad inmediata del procedimiento fotográfico (BRUnET, 2000, 102). Arago recordaba, en efecto, la exactitud y la rapidez de la fotografía "chacun songera à l'immense parti qúon aurait tiré, pen- 
dant l'expédition d’Égypte, d'un moyen de reproduction si exact et si prompt" (ARAGO, 1839). También Gay-Lussac señaló, en el mismo año de 1839, cómo "la perspective du paysage, de chaque objet, est retracée avec une exactitude mathématique" (GAY-Lussac, 1939).

\section{VI-. CONCLUSIONES.}

La fotografía proporcionó a la arqueología del s. XIX y de buena parte del s. XX la ratificación o demostración de las teorías más variadas. Su consideración de prueba y documento veraz fue, como hemos visto, uno de los principales motivos de su rápida adopción por parte de muchos eruditos. La fotografía apoyaba el discurso arqueológico y ayudó en el proceso de reconocimiento de la Arqueología como una disciplina científica. Metodológicamente el nuevo invento intervino, de manera fundamental, en el proceso de clasificación arqueológica de todos los restos. Las aportaciones básicas de la arqueología de la época se basaron en un triángulo de relaciones recíprocas entre los tipos, la tecnología y la estratigrafía. De la conjunción de estas tres nociones emergió en la arqueología de la época el positivismo arqueológico de Mortillet y Montelius (SCHNAPP, 1991, 20). Algunos de ellos, como Mortillet incorporaron, desde momentos muy tempranos, el registro y la utilización de la fotografía en sus trabajos. El crédito que se le concedió hizo comprender a los eruditos que la imagen fotográfica serviría para sostener sus hipótesis, sobre todo en caso de oposición o debate (FEYLER, 1993, 189). Así, las efectuadas en el yacimiento no sólo permitían el registro de los trabajos, sino que podían convertirse en el documento para la demostración de la consiguiente teoría del autor.

En efecto, considerando el uso de la fotografía por parte de los arqueólogos descubrimos cómo algunas de sus primeras aplicaciones estuvieron motivadas por los problemas, debates y polémicas que los nuevos hallazgos suscitaron. Así, por ejemplo, el helenista Victor Bérard trabajó, a principios del s. XX, en el establecimiento de lo que, en su opinión, había sido el itinerario de Ulises. Para plasmar e ilustrar estos recorridos por el Mediterráneo recurrió al fotógrafo Fred Boisonnas (Ver Lám. 6) quien, durante 1.912, viajó con él efectuando un número importante de tomas (FEYLER, 1993, 188).

También Salzmann nos dejó su opinión sobre la "convicción" que proporcionaba la fotografía. Así, en la introducción de su obra podemos leer cómo "les photographies ne sont plus des récits, mais bien des faits doués d'une brutalité concluante" (FOLIOT, 1986, 34; FrizOT, 1994, 382).
En esta frase, enunciada a mediados del siglo XIX, encontramos paradigmáticamente el principio de la fotografía como demostración de un hecho, de una realidad o de una teoría determinada. Esta aplicación de la fotografía tendría, en el futuro, unas repercusiones muy notables.

Los investigadores franceses protagonizaron también uno de los momentos fundamentales en el reconocimiento de la Cultura Ibérica y de una de sus máximas representaciones artísticas; la Dama de Elche. En efecto, L. Heuzey presentó en 1897, en un informe leído ante la Académie des Inscriptions et Belles Lettres, la escultura descubierta recientemente. Como apoyo para su presentación Heuzey recurrió a la fotografía. Este recurso cobra pleno sentido si tenemos en cuenta que la Dama de Elche se inscribía en una cultura, la ibérica, cuya autenticidad se había puesto en duda dentro de los círculos eruditos europeos. La nueva escultura corría el peligro de que fuese calificada como un falso más. Apoyando sus hipótesis Heuzey declaraba "ĹAcadémie pourra en juger par una photographie que M. Paris a jointe à sa communication" (HEUZEY, 1897, 3). Con esta finalidad, la primera página del artículo incluía una vista de la Dama de Elche mirando a la derecha. La toma, con un encuadre bastante oblicuo, se había efectuado desde un punto ligeramente superior, al igual que la iluminación de la pieza. Bajo la fotografía podía leerse Buste antique d Elche. Sculpture gréco-phénicienne de lEspagne, Mission de M. Pierre Paris, Phototypie Berthaud, Paris (Heuzey, 1897, 1). Heuzey recurrió a una segunda fotografía, que representaba el reverso de la figura, para hacer "algunas indicaciones complementarias". En su opinión la Dama de Elche era un busto y no la parte superior de un escultura de cuerpo entero. Se basaba para ello en la preparación del bloque, ligeramente rehundido por abajo, que no parecía apuntar la posibilidad de una figura de cuerpo entero (HeuZEY, 1897, 7). En su opinión se trataría de un busto (HEuzeY, 1897, 6). Las fotografías dejaban observar algunos detalles significativos como la presencia de la pintura roja "en los labios y algunas partes del peinado y de la vestimenta" (Heuzey, 1897, 4).

Gracias al descubrimiento de P.Paris Heuzey señalaba cómo "hoy estamos autorizados a decir que hubo un arte antiguo español o, si queremos, ibérico, al igual que hemos de admitir un arte chipriota y uno etrusco" (Heuzey, 1897, 5). Ésta era la hipótesis que, mediante diversos argumentos y fotografías, quería defender. Heuzey la denominó "la demi-civilisation gréco-phénicienne" que precedió en España a la conquista romana (HeuZey, 1897, 6). La existencia de esta cultura específica era, sin duda, el aspecto más difí- 


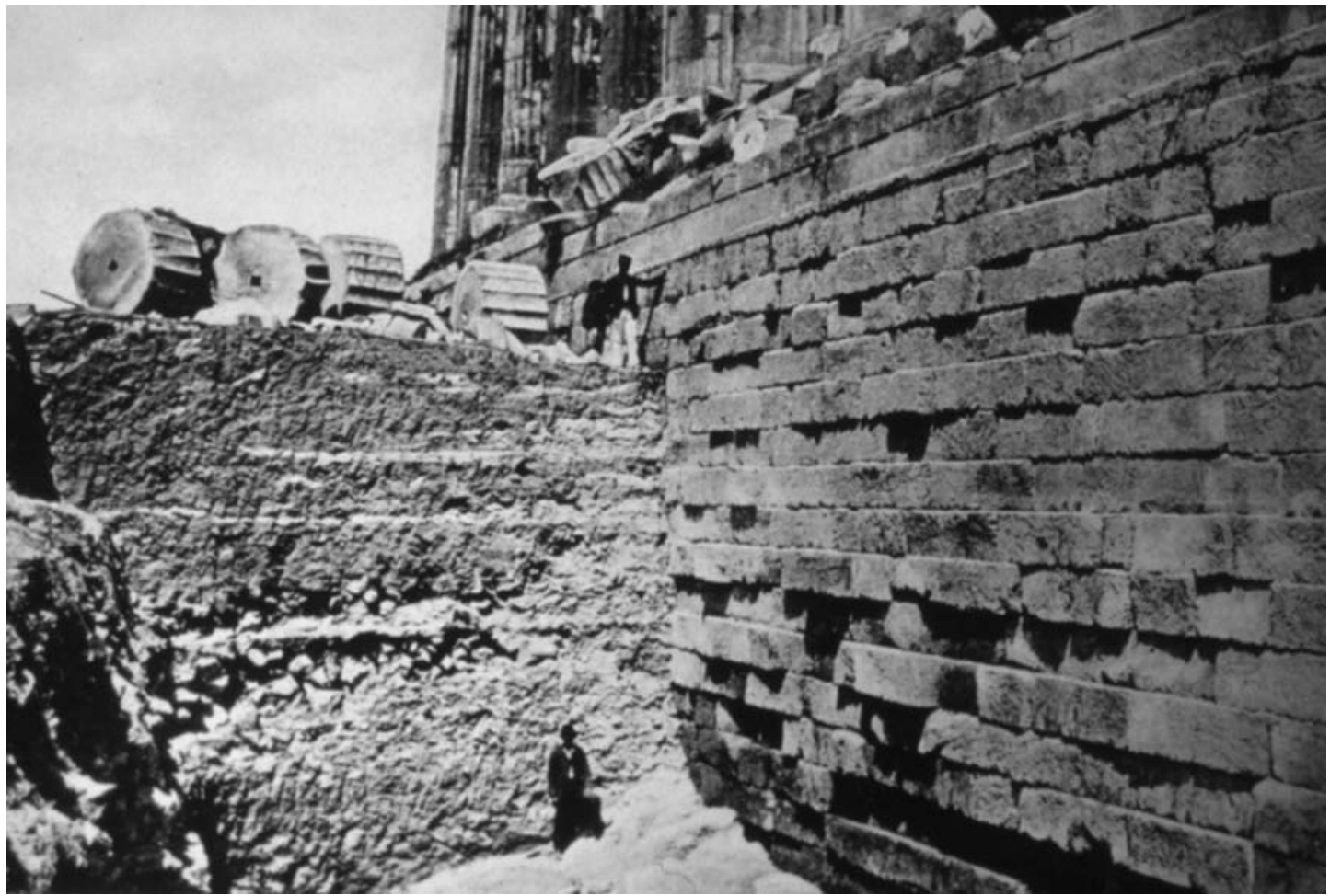

Lámina 8: Vista de los trabajos emprendidos por el arqueólogo Cavvadias en la acrópolis de Atenas, durante los que descubrió un importante conjunto de 15 korai. En Die Ausgrabung der Akropolis vom Jahre 1885 bis zum jahre 1890, Lámina L.

cil de admitir por parte de algunos eruditos. El descubrimiento de la Dama de Elche suponía el final del cuestionamiento de la autenticidad de las esculturas del Cerro de los Santos y, con ello, de la propia cultura ibérica (Heuzer, 1897, 5).

En definitiva y durante el período de tiempo que hemos examinado se produjo en Francia uno de los cambios fundamentales de los estudios históricos del s. XX: el paso del fait brut de la historia positivista al fait élaboré de la Nouvelle Histoire (ABOut, ChÉroux, 2002, 26). En este proceso la fotografía intervino permitiendo un mejor conocimiento de la cultura material y de las manifestaciones arquitectónicas de las culturas que se estaban descubriendo. Como documento, idóneo como hemos visto dentro de los planteamientos positivistas, la fotografía favoreció la clasificación, caracterización y progresiva definición de los materiales de la antigüedad. Su papel fue, pues, considerable dentro de las pautas que iban a caracterizar la nueva ciencia arqueológica a partir de la década de los años 60 del s. XIX.

A partir de la segunda década del s. XX, los intereses de la investigación arqueológica pasaron a estar dominados por los planteamientos histórico-culturales (TRIGGer, 1989) y por la identificación de las diferentes culturas arqueológicas. El interés por relacionar los yacimientos excavados con pueblos o etnias, la necesidad de conocer su cultura material, de establecer cronologías y caracterizar las diferentes fases, etc., hizo que se empezase a valorar en mayor medida la estratigrafía. El contexto estratigráfico, la secuencia de momentos y fases que marcaba pasaron a ser, en efecto, claves según las nuevas exigencias de la investigación arqueológica.

Consecuentemente con ello se acentuó el cambio de forma y contenido que venía detectándose en la parte gráfica de las publicaciones arqueológicas. La fotografía testimonia, en esta evolución, los cambios experimentados por los propios métodos de investigación arqueológica. Junto a las anteriores vistas generales tuvieron mayor relevancia primeros planos de las principales secuencias estratigráficas de cada sector o habitación (Ver Lám. 8). La fotografía era ahora el punto de apoyo, o referencia, para las diferencias entre las sucesivas fases, argumentos sobre los que el autor iba a apoyar sus conclusiones históricas.

Sin embargo, el apoyo y la corroboración que proporciona la fotografía en estos procesos no es inocente. La esencia de la fotografía consiste en la selección. Frente a la realidad, frente al total del yacimiento, nos transmite un fotograma, un fragmento. Éste es presentado, interpretado y valorado como algo global, cuando su contenido 
depende de multitud de factores. Y, como selección, siempre supone la priorización de unos aspectos respecto a otros.

En este sentido la imagen fotográfica, más que un "reflejo" de la realidad, es una construcción. Cuando es realizada por el propio investigador, la imagen resultante es claramente indicativa de su visión, intereses, objetivos y de los argumentos centrales sobre los que va a apoyar su teoría. $\mathrm{Y}$ es precisamente esta característica de "estrategia de representación" la que convierte a la imagen fotográfica en un documento objeto de análisis para el historiador.

\section{Bibliografía.}

About, I. ; Cheorux, Cl. (2002): «L'histoire par la photographie», Études Photographiques, n ${ }^{\circ}$, Noviembre 2002, 9-33, París.

Arago, F. (1839): "Rapport à la Chambre des Députés, séance du 3 Juillet 1839", Historique et description des procédés du daguerréotype et du diorama, París.

Aubenas, S. (1999): "Les photographes en Orient, 18501880", en Aubenas, S., y Lacarrière, J., Voyage en Orient, Bibliothèque national de France, 18-42, París.

Aubenas , S. (1999b): "Les Bisson au service des arts et des sciences", en Chlumsky, M., Eskildsen, U. y Marbot, B., Les Frères Bisson photographes. De flèche en cime, 18401870, 184-187, Bibliothèque nationale de France, París.

Binetruy, M-S. (1994): De lart roman à la Préhistoire des sociétés locales à $t$ Institut, Itinérarires de Joseph Déchelette, Lyon.

Boucher de Perthes, J. (1847-1864): Antiquités celtiques et antédiluviennes. Mémoire sur l industrie primitive et les arts à leur origine, París.

Bourdé, G.; Martin, H. (1983): Les écoles historiques, París.

Broncano Rodríguez, S; Blánquez Pérez, J., 1985: El Amarejo, Bonete (Albacete), Ministerio de Cultura, Madrid.

Brunet, F. (2000): La naissance de lidée de photographie, París.

Bulliot, J.G. (1899): Fouilles de Mont Beuvray de 1867 à 1895, París.

CHRIST, Y. (1980): "Documents, témoins d'une architecture disparue", en Monuments Historiques, 110, 69-74.

Clarke, G. (1997): The Photograph, Oxford History of Art, Oxford.

Cros, G.; Heuzey, L. y Thureau-Dangin, F. (1914): Nouvelles fouilles de Tello, Mission Française en Chaldée, París.

Darwin, Ch. (1859): Origin of species by means of natural selection or the Preservation of Favoured Races in the Struggle for life, Londres.

Deonna, W. (1922): "Ĺarchéologue et le photographe", en Revue Archéologique, T. XVI, 85-110.

Dewachter, M.; Oster, D. (1987): Un voyageur en Égypte vers 1850. "Le Nil" de Máxime du Camp, Illustré d après 70 Calotypes originaux de Máxime du Camp, par 20 documents $d$ archives et 15 aquareles de Prisse d Avennes, París.

Digeon, C. (1959): La crise allemande de la pensée franVaise, París.

De Longpérier, A. (1875): "Sur les antiquités de lî̂le de Santorin", en Comptes Rendus de lAcadémie des Inscriptions et Belles-Lettres, 182-184, París.

DE SAulCY, F. (1953): Voyage autour de la mer Morte et dans les terres bibliques, 3 vol. París.

DÉCHelette, J. (1904a): Les fouilles de Mont Beuvray de 1897 a 1901. Compte rendu suivi de L'inventaire général des monnaies recueillis à Beuvray et du Hradicht de Stradonoc, en Bohème, étude d'archéologie comparée avec un pal, 26 planches hors texte et plusieurs figures, Picard, París.

DÉCHeletTe, J. (1904b): Les vases ornés de la Gaule romaine: Narbonnaise, Aquitaine et Lyonnaise, París.

DÉChelette, J. (1908): Manuel d archéologie préhistorique celtique et gallo-romaine, Picard, París.

Déchelette, J. (1909): "Essai sur la chronologie Préhistorique de la Péninsule Ibérique”, en Revue Archéologique, París.

Delporte, H. (1994): "Préface", en Binetruy, M-S., De l art roman à la Préhistoire des sociétés locales à $l$ Institut, Itenérarires de Joseph Déchelette, 2-4, Lyon.

Cavvadias, P. y Kawerau, G. (1906): Die Ausgrabung der Akropolis vom Jahre 1885 bis zum jahre 1890, Mainz.

Chéné, A.; Foliot, PH.; Réveillac, G. (1986): De la Photographie en Archéologie, Tesis Doctoral inédita Universidad de Provence «Lettres et Sciences Humaines".

Chlumsky, M. (1999): "Espace et exactitude: la photographie d'architecture des frères Bisson", en CHLumskY, M., Eskildsen, U. y Marbot, B., Les Frères Bisson photographes. De flèche en cime, 1840-1870, 81-101, París.

Feyler, G. (1993): Le fonds de photographies anciennes de l Institut darchéologie classique de lUniversité de Strasbourg (Fonds Michaelis), Tesis Doctoral inédita enero 1993, Estrasburgo.

Foliot, Ph. (1986): "Histoire de l'image archéologique depuis l'invention jusqu'à nos jours”, en Chéné, A.; Foliot, Ph. y Réveillac, G., De la Photographie en Archéologie, Tesis doctoral inédita, 14-215, Universidad de Provenza. 
FrizOT, M. (1994): "États de choses. L'image et l'aura", en Frizot, M. (Éd.), Nouvelle histoire de la photographie, 370-385, París.

GAY-LuSSAC, J.L. (1839): "Rapport" en Historique et description des procédés du daguerréotype et du diorama, 31-35, París.

Gran-Aymerich, E. (1998): Naissance de TArchéologie Moderne 1798-1945, París.

Gran-Aymerich, E. (2001): Dictionnaire biographique d Archéologie 1798-1945, París.

Heuzey, L. (1897): "Le buste d'Elche et la Mission de M. Pierre Paris en Espagne", Comptes Rendus de l Académie des Inscriptions et Belles Lettres.

Heuzey, L., y Daumet, H. (1876): Mission archéologique en Macédonie, París.

Jammes, I. (1981): Blanquart-Evrard et les origines de lédition photographique française, Ginebra.

Kracauer, S. (1927): Die Photographie, Berlín.

KraCAUER, S. (1967): History: things before the Last, Londres.

LACAN, E. (1856): Esquisses photographiques, à propos de $l$ Exposition universelle et de la guerre d Orient, París.

NeCCI, M. (1992): La fotografia archeologica, Roma.

NIR, Y. (1985): The Bible and the Image, History of photography in the Holy Land 1839-1899, University of Pennsilvania Press, Philadelphia.

Pasamar Alzuria, G. y Peiró, I. (1987): Historiografía y práctica social en España, Zaragoza.

Pereira Sieso, J. (1987): La cerámica pintada a torno en Andalucía. Siglos VI-III a.C. Cuenca del Guadalquivir, Universidad Complutense de Madrid.

Perrot, G.; Guillaume, Delbet, 1872: Exploration archéologique de la Galatie et de la bithynie d une part, de la Mysie, de la Phyrgie, de la Cappadoce et du Pont d'autre part, exécutée en 1861, París.

Prestwich, J. (1859): In the occurrence of Flint implements, Londres.

Renan, E. (1864-1874): Mission en Phénicie, París.

Renan , E. (1890): "Ĺavenir de la science. Pensées de 1848” en H. Psichari (ed.), Oeuvres complètes dE. Renan, t. III, París.
Renfrew, C. y Bahn, A. (1993): Arqueología. Teoría, métodos y práctica, ed. Original inglesa 1991, Madrid.

Rouillé, A. (1986): "La exploración fotográfica del mundo en el siglo XIX”, en Lemagny y Rouillé, Histoire de la photographie, Bordas. Ed. española: Historia de la fotografía, 53-59, Barcelona

Rouillé , A. (1989): La photographie en France. Textes et controverses: une anthologie 1816-1871, París.

SARzec, E. DE; Heuzey, L. (1884-1912): Découvertes archéologiques en Chaldée, dos. Vol. París.

Schnapp , A. (1991): "Modèle naturaliste et modèle philologique dans l'archéologie européenne du XVI ème siècle au XIX ème siècle", en ARCE, J. y Olmos Romera, R. (eds.), Historiografía de la Arqueología y de la Historia Antigua de España, 19-24, Congreso Internacional Madrid 1988, Madrid.

SChnApr, A. (1993): La conquête du passé. Aux origines de t archéologie, París.

SchnAPP , A. (1997): "L’archéologie française entre identité nationale et identité culturelle", en SCHNAPP, A. (ed), Une archéologie du passé récent?, 5-21, París.

STARL, T. (1994): "Un nouveau monde d'images. Usage et diffusion du daguerréotype", en FrizOT, M. (Éd.): Nouvelle histoire de la photographie, 33-58, París.

Trigger, B.G. (1989): A History of Archaeological Thought, Ed. En castellano (1992) Historia del pensamiento arqueológico, Crítica, Barcelona.

VVAA. (1852): "Égypte, Nubie, Palestine et Syrie, dessins photographiques recueillis par M. Du Camp, format petit in-folio, Gide et Baudry, París", Revue archéologique, 1852, 192, París.

VV.AA. (1982): Félix de Saulcy (1807-1880) et la Terre Sainte. Archives et Documents d une mission archéologique, París.

WEy, F. (1851): "De l'influence de l'héliographie su les beaux-arts", La Lumière, $\mathrm{n}^{\circ} 1$, Febrero, París. 